\title{
Elementary Reactions and Their Role in Gas-Phase Prebiotic Chemistry
}

\section{Nadia Balucani}

Dipartimento di Chimica, Università degli Studi di Perugia, 06123 Perugia, Italy;

E-Mail: nadia.balucani@unipg.it; Tel. +39-075-585-5513; Fax: +39-075-585-5606

Received: 4 April 2009; in revised form: 13 May 2009 / Accepted: 15 May 2009 /

Published: 19 May 2009

\begin{abstract}
The formation of complex organic molecules in a reactor filled with gaseous mixtures possibly reproducing the primitive terrestrial atmosphere and ocean demonstrated more than 50 years ago that inorganic synthesis of prebiotic molecules is possible, provided that some form of energy is provided to the system. After that groundbreaking experiment, gas-phase prebiotic molecules have been observed in a wide variety of extraterrestrial objects (including interstellar clouds, comets and planetary atmospheres) where the physical conditions vary widely. A thorough characterization of the chemical evolution of those objects relies on a multi-disciplinary approach: 1) observations allow us to identify the molecules and their number densities as they are nowadays; 2) the chemistry which lies behind their formation starting from atoms and simple molecules is accounted for by complex reaction networks; 3 ) for a realistic modeling of such networks, a number of experimental parameters are needed and, therefore, the relevant molecular processes should be fully characterized in laboratory experiments. A survey of the available literature reveals, however, that much information is still lacking if it is true that only a small percentage of the elementary reactions considered in the models have been characterized in laboratory experiments. New experimental approaches to characterize the relevant elementary reactions in laboratory are presented and the implications of the results are discussed.
\end{abstract}

Keywords: gas-phase prebiotic chemistry; nitriles; organosulfur compounds 


\section{Introduction}

In the sequence of steps which are believed to have led from elementary particles to the emergence of life, an important one is certainly the formation of simple prebiotic molecules from parent species abundant in the Universe. The aggregation of $\mathrm{H}, \mathrm{O}, \mathrm{C}, \mathrm{N}, \mathrm{S}$ and other atoms into molecules and the subsequent chemical evolution are occurring also now in the Universe, as witnessed by the identification of more than one hundred molecules in the interstellar clouds (encompassing also prebiotic molecules such as hydrogen cyanide, glycolaldehyde, formamide and even, tentatively, glycine) and by the gas-phase chemical evolution of the atmospheres of several solar objects such as Titan. Certainly, these processes might seem relatively simple compared to the other unknown phenomena that have led to the first living organisms. Nevertheless, the formation mechanisms of many of the observed gaseous prebiotic molecules and radicals are far from being understood, while a comprehension of those processes can certainly help to set the stage for the emergence of life to occur.

If we compare the elemental composition of the Universe and that of a living cell, a remarkable difference is evident, especially as far as the abundances of carbon and nitrogen are concerned. And not only is the elemental composition different, but also the type of molecules: mostly large and complex in a cell, rare and simple in the Universe. Clearly a chemical differentiation has taken place, firstly in the formation and evolution of solar systems in star-forming regions and then in the passage from inanimated matter to living entities. A series of intermediate molecular species, characterized by some complexity and all the appropriate "ingredients", might be the link between these extremely different environments. In Table 1 are grouped a series of molecules which can be synthesized in abiotic processes (e.g. in the gas phase), but might be prebiotic in nature [1,2] and which have been identified in extraterrestrial gaseous environments (of course this does not mean that they are permanent gases under the typical conditions of Earth). For instance, gaseous molecules containing a $\mathrm{C}-\mathrm{N}$ bond (such as $\mathrm{HCN}, \mathrm{HC}_{3} \mathrm{~N}$ and $\mathrm{CH}_{3} \mathrm{CN}$ ) are potential precursors of aminoacids or nucleobases in the presence of water, while molecules containing a $\mathrm{C}-\mathrm{O}$ bond might be the building blocks for the synthesis of sugars and aminoacids (notable examples are glycol-aldehyde and ethylene glycol).

Table 1. Simple gas-phase molecules and their possible relation to biologically relevant molecules.

\begin{tabular}{lll}
\hline \multicolumn{1}{c}{ Gas-phase molecules } & \multicolumn{1}{c}{ Potential precursor of } & \multicolumn{1}{c}{ Examples } \\
\hline with C-N bonds & Aminoacids and Nucleobases & $\mathrm{HCN}, \mathrm{CH}_{3} \mathrm{CN}, \mathrm{C}_{2} \mathrm{~N}_{2}, \mathrm{HCCCN}$, \\
& & $\mathrm{CH}_{2} \mathrm{NH}, \mathrm{C}_{2} \mathrm{H}_{3} \mathrm{CN}$ \\
with C-O bonds & Sugars and Aminoacids & $\mathrm{H}_{2} \mathrm{CO}, \mathrm{CH}_{3} \mathrm{COH},\left(\mathrm{CH} \mathrm{CH}_{2}\right.$ \\
with C-C multiple bonds & Long carbon chain molecules and $\mathrm{PAHs}$ & From $\mathrm{C}_{2} \mathrm{H}_{2}$ up to polyynes \\
+ other molecules such as $\mathrm{H}_{2} \mathrm{O}, \mathrm{NH}_{3}, \mathrm{H}_{2} \mathrm{~S}, \mathrm{NH}_{2} \mathrm{CN}, \mathrm{HCOCN}, \mathrm{NH}_{2} \mathrm{CH}_{2} \mathrm{CN}, \mathrm{HCONH}_{2}, \mathrm{CH}_{3} \mathrm{CONH}_{2}$, \\
\hline
\end{tabular}

Finally, gaseous molecules with multiple $\mathrm{C}-\mathrm{C}$ bonds provide the skeleton for long carbon chain molecules and are possible precursors of polycyclic aromatic hydrocarbons (PAHs). Other molecules which might be synthesized in the gas phase are water, ammonia, formamide, sulfur and phosphorus compounds etc. 
How these molecules, or even more complex ones, could have reached or been developed on our planet is a matter of debate. Essentially two possible scenarios have been suggested so far, the endogenous synthesis and the exogenous synthesis $[3,4]$. According to some theories dating back to the 'warm little pond' suggested by Darwin and the 'primordial soup' idea by Oparin, the synthesis of organic molecules occurred directly in our planet starting from simple parent molecules (such as $\mathrm{N}_{2}$ or $\mathrm{NH}_{3}, \mathrm{H}_{2} \mathrm{O}$ or $\mathrm{H}_{2}, \mathrm{CH}_{4}$ or $\mathrm{CO}_{2}$ and others) [5-9] which constituted a sort of secondary atmosphere of Earth, after the primordial one was swept away during the first period of the solar system life. There are some discussions on the composition of the atmosphere back then, which could be in a reduced or oxidized (or intermediate) state [7,8], and also on the role of the possible chemical processes, which could have been induced by various sources of energy, such as intense lightning, energetic solar photons, radioactivity, intense volcanic activity, and shock waves of different kinds [7-9]. This is the so-called endogenous synthesis vision, as the prebiotic species would have been synthesized directly on Earth from simple parent molecules. This vision gained support more than 50 years ago by the ground-breaking experiment of Stanley Miller [5], an experiment having also the merit of demonstrating that an abiotic synthesis of prebiotic molecules is possible starting from very simple gaseous parent molecules [7]. For completeness, it should be mentioned that there is an alternative endogenous synthesis theory, where gas-phase reactions are not involved, according to which some organic synthesis could have taken place in the proximity of oceanic hydrothermal vents because of the relative abundance of methane and ammonia [10].

The alternative scenario is the exogenous synthesis, according to which most of the organic molecules came from space, the carriers being comets, asteroids, meteorites or even interplanetary dust particles ([11-16] and references therein). The rationale behind this suggestion is that plenty of simple organic molecules have been identified in all these objects. The idea is that they were first synthesized in the nebula from which the formation of the solar system originated. Those molecules were then incorporated in comets and meteorites far from the central star and then reached our planet [12], where they could evolve in an aqueous medium after the terrestrial temperature decreased. In favor of this scenario there is the observation of many organic molecules in the interstellar clouds, including several star-forming regions. Amongst the more than 150 molecules identified in the interstellar medium [17], in fact, only 36 do not contain carbon atoms and most of the molecules listed in Table 1 (e.g. glycolaldehyde, ethylene glycol, $\mathrm{HCN}, \mathrm{HC}_{3} \mathrm{~N}$, formamide, methanimine) have been identified in the interstellar medium. In addition, complex, organic to some extent, molecules have been detected in comets, interplanetary dust particles and, especially, carbonaceous meteorites [11-16]. Following the observation, it remains to be demonstrated where and how these molecules are formed, whether they can be preserved during the early phases of solar-type star formation and in the solar nebula $[11,12,18]$, how they can be incorporated into comets and meteorites and whether they can survive their entry into the terrestrial atmosphere [11,12]. The attractiveness of this theory is that, if it is proved that there is a link between prebiotic molecules synthesized in space and the appearance of life on Earth, a hint on the possibility that life is a widespread phenomenon in the Universe, rather than a local, fortuitous case, can be gained.

Whether in a planetary atmosphere or in the interstellar clouds (ISCs) that precede the formation of solar systems, the observation of prebiotic molecules in a wide variety of gaseous extraterrestrial objects, where physical conditions vary to a large extent, implies that gas-phase chemistry plays a role 
in their synthesis. Different types of molecular processes are believed to be involved, including radiative association and recombination, surface-induced processes [19], photon- or particle-induced ionization and ion-molecule reactions [20], photon- or particle-induced dissociation and radicalmolecule reactions [20]. The concomitance of all these phenomena and the complexity of their environments require a modelling approach, where all the relevant molecular processes compatible with the boundary conditions should be considered with the appropriate parameters that describe them. This strategy has been pursued by several research groups to model the chemical evolution of interstellar clouds, planetary atmospheres and cometary comae (see for instance [21-30]). For the modeling of these complex networks of elementary reactions, a number of experimental parameters are needed and, therefore, the molecular processes necessary to construct a realistic model should be fully characterized in laboratory experiments. A survey of the available literature reveals, however, that much information is still lacking if it is true that only a small percentage of the elementary reactions included in the models have been characterized in laboratory experiments under conditions that simulate those prevailing in the various environments. To understand the reason for that, let us briefly examine two typical environments where this chemistry takes place, that is, ISCs and the atmospheres of planets and satellites of our solar system.

The ISCs are essentially formed by gaseous matter [21-26,31,32], with a small percentage (1\% by mass) of dust particles. The average kinetic energy is typically confined to $0.8 \mathrm{~kJ} \mathrm{~mol}^{-1}$ (corresponding to a temperature of $100 \mathrm{~K}$ ) in diffuse clouds and $0.08 \mathrm{~kJ} \mathrm{~mol}^{-1}$ (corresponding to a temperature of $10 \mathrm{~K}$ ) in dark molecular clouds and, therefore, the formation of molecular species via gas-phase reactions can only involve reactions without appreciable activation energy. For this reason, since the first observation of molecules in ISCs, ion-molecule reactions have been considered to play a central role [29,32], as they are usually characterized by null activation energy and can, therefore, be fast at very low temperatures. Nevertheless, only a small percentage of atomic and molecular species are ionized in the clouds. Neutral-neutral gas-phase reactions have been correctly included in the modeling of ISC chemistry only after it has been possible to measure their rate constant down to very low temperatures (as low as $15 \mathrm{~K}$ ) by means of the CRESU (the French acronym for Cinétique de Réaction en Ecoulement Supersonique Uniforme) technique [33]. From these studies experimental evidence has been obtained that some reactions involving atomic or radical species (such as atomic carbon or $\mathrm{CN}$, $\mathrm{C}_{2} \mathrm{H}$ and $\mathrm{C}_{4} \mathrm{H}$ radicals) are very fast, with rate constants in the gas kinetics range, even at very low temperatures [33]. Also, the results from this technique have pointed out that the extrapolation at very low temperatures of the Arrhenius dependence of the rate constant outside the range of $\mathrm{T}$ investigated is not warranted and important deviations from it have been observed [34,35]. The inclusion of several fast neutral-neutral reactions in the complex reaction networks that model the chemical evolution of ISCs is a recent advance in the field [22,25]. In principle, however, all the possible reactions should be investigated at the low temperature of the various interstellar objects.

After numerous missions, airborne and ground-based observations, plenty of information is available on the structure and chemical composition of the atmospheres of the planets of our solar system. Similarly to the atmosphere of Earth, the atmospheres of the other planets (or satellites, such as Titan) can be described as giant photoreactors, where the energy deposited mainly by solar photons, but also by cosmic rays and other energetic particles, drives a complex gas-phase chemistry [27,3648]. In this case as well, to account for the chemical composition of the atmospheres, complex models 
including physical parameters, such as vertical transport, wind transport and temperature profiles, have been developed. These models are usually referred to as photochemical models, because the main source of energy that drives the various phenomena considered are solar photons. Among others, the atmosphere of Saturn's massive moon Titan has received considerable attention because it is considered to be somewhat reminiscent of the primeval atmosphere of Earth [49,50]. In an atmosphere mainly composed by molecular nitrogen with a small percentage of methane, the detection of gasphase nitriles (in trace amounts of a few parts per billion) has attracted a lot of interest, since these species are thought to be key intermediates towards the formation of biologically relevant molecules $[1,251,52]$. The surface temperature of Titan is $\sim 94 \mathrm{~K}$ and even in the upper stratosphere the temperature does not exceed $187 \mathrm{~K}$. Therefore, water is mainly in the solid state and the absence of liquid water prevents the evolution of life as we know it. On the other hand, exactly because of the absence of a biosphere, Titan provides us with the unique opportunity to investigate a chemical environment probably close enough to the primitive terrestrial atmosphere. In other words the study of the chemical evolution of Titan's atmosphere can help us to understand how biologically active molecules and their nitrile precursors can be synthesized in a mildly reducing atmosphere [49], possibly resembling that of our planet before the emergence of life drastically changed its composition. Numerous photochemical models of increasing complexity have attempted to describe the atmospheric composition of Titan and important improvements have been achieved after the results of the CassiniHuygens mission [41-48]. Nevertheless, even the latest models [45,48] include several elementary reactions (unimolecular, bimolecular and termolecular) never studied in the laboratory, with parameters estimated by analogy with 'similar' ones, whereas other elementary reactions have been included with the laboratory parameters measured under different conditions (particularly temperature). The extrapolation of the experimental data to temperatures different from those actually used in the experiments is not warranted [35], while the analogy with similar systems can lead to completely erroneous evaluations [34].

In the following sections, an overview will be given of the two experimental approaches that have allowed us to reach a better description of neutral-neutral gas-phase reactions of importance in the chemical modeling of ISCs and the atmosphere of Titan. This review paper is not meant to be a comprehensive survey of the very active and productive fields of prebiotic chemistry and astrochemistry, where important contributions are also made by theoretical investigations (see, for instance, [53-55]), and the focus will be only on neutral-neutral bimolecular reactions. Firstly, the principles of the CRESU technique, that has finally allowed the measurements of several reaction rate constants at appropriately low temperatures, will be illustrated. This technique, as well as other typical kinetics techniques, usually provide us with the reactant disappearance rate constants, but more rarely are able to determine the nature of the reaction products and their branching ratio. This is, however, a very important piece of information, because in the reaction networks used in the models the products of one reaction are going to be the reagents of a subsequent one. An alternative approach is necessary and the best opportunity is furnished by free-collision experiments. This is the realm of reaction dynamics, a discipline which provides us with the most detailed knowledge of a gas-phase reaction and aims to verify whether a specific reaction pathway and its related products are really accessible by the system. In this respect, the crossed molecular beam (CMB) technique, especially when coupled to universal mass spectrometric (MS) detection, has proved to be an extraordinary tool [56]. Finally, the 
results on several reactive systems and their connection with the understanding of gas-phase prebiotic chemistry will be illustrated.

\section{The CRESU Technique}

As pointed out in the Introduction, it is imperative to measure the rate constants of the potentially relevant reactions at the low temperatures typical of the ISCs and also of the atmospheres of the other objects of the solar system (with the only exception of Venus, all other atmospheres are characterized by an average temperature lower than that of our planet). There are two experimental approaches to cool gases to low temperatures and study their reactions: cryogenic cooling and expansion methods [33,57-59]. Cryogenic cooling is a simple approach that consists in cooling the entire reaction vessel at the desired temperature. This approach, however, is limited by the saturation vapour pressure of the reactant gases and there are practically no reactions that could be investigated at $10-20 \mathrm{~K}$ without condensation of the reactants on the walls of the refrigerated container. The alternative method to cool the reactant gases is the use of a supersonic expansion. The expansion from a high pressure zone to a low pressure one is an adiabatic, isentropic process which converts the thermal energy of the gas into kinetic energy. The use of a collimating axisymmetric, converging-diverging Laval nozzle, leads to the production of a cold and uniform supersonic flow of gas [33,57-59]. This is the approach used in the CRESU technique. Comprehensive descriptions of the principles of this technique can be found in several reviews $[33,57-59]$. An important characteristic of the expansion through a Laval nozzle is that a relatively dense medium $\left(10^{16}-10^{17} \mathrm{~cm}^{-3}\right)$ is formed, in which the temperature and number density are constant along the axis of the flow. Different nozzles and carrier gases are used to produce a specific flow temperature and the supersonic flow regime is maintained as such also when $1-2 \%$ of additional gases are added. The chemically unstable reactants in the gas mixture (generally an atomic [60-62] or radical [63-70] species, but also unstable closed-shell species such as $\mathrm{C}_{2}$ [71,72]) are generated via pulsed laser photolysis (PLP) of a molecular precursor. In a typical CRESU arrangement, the decay rate of the unstable reactant is followed by laser-induced fluorescence (LIF), see Figure 1. The photolysis and probe pulsed lasers co-propagate along the axis of the supersonic flow. On the one hand, the photolysis laser produces a homogeneous concentration of the desired radical starting from a suitable molecular precursor. On the other hand, the probe laser monitors the formed radicals by exciting them to an upper electronic state. The resulting fluorescence is collected at $10-50 \mathrm{~cm}$ downstream of the Laval nozzle exit. For a given concentration of the reaction partner, the decay rate of the radical is observed by varying the delay time between the pulse from the photolysis laser and the pulse from the probe laser. The fluorescence signal decreases with the delay time exactly because the radicals are consumed in the reaction during their transit along the flow. A severe limit of the CRESU technique is that it cannot be used for reactions with room temperature rate constants smaller than $10^{-12} \mathrm{~cm}^{3}$ molec $^{-1} \mathrm{~s}^{-1}$. This order of magnitude is imposed by the fact that the supersonic flow is maintained uniform over a distance of a few tens of centimetres. This implies a time scale of $100-500 \mu$ s within which the change of concentration of the atom/radical reactant has to be detected. In the classical CRESU technique, an extensive pumping system is required. To reduce the pumping system, a pulsed Laval nozzle technique was developed and used to study bimolecular reactions down to $53 \mathrm{~K}[73-83]$. 
Figure 1. A schematic view of the PLP-LIF CRESU apparatus for the study of neutralneutral bimolecular reaction. Reprinted from Canosa, A.; Goulay, F.; Sims, I.R.; Rowe, B.R. Gas phase reactive collisions at very low temperature: recent experimental advances and perspectives. In Low Temperatures and cold molecules, Copyright 2008, published with permission from World Scientific Publishing Co. Pte. Ltd, Singapore.

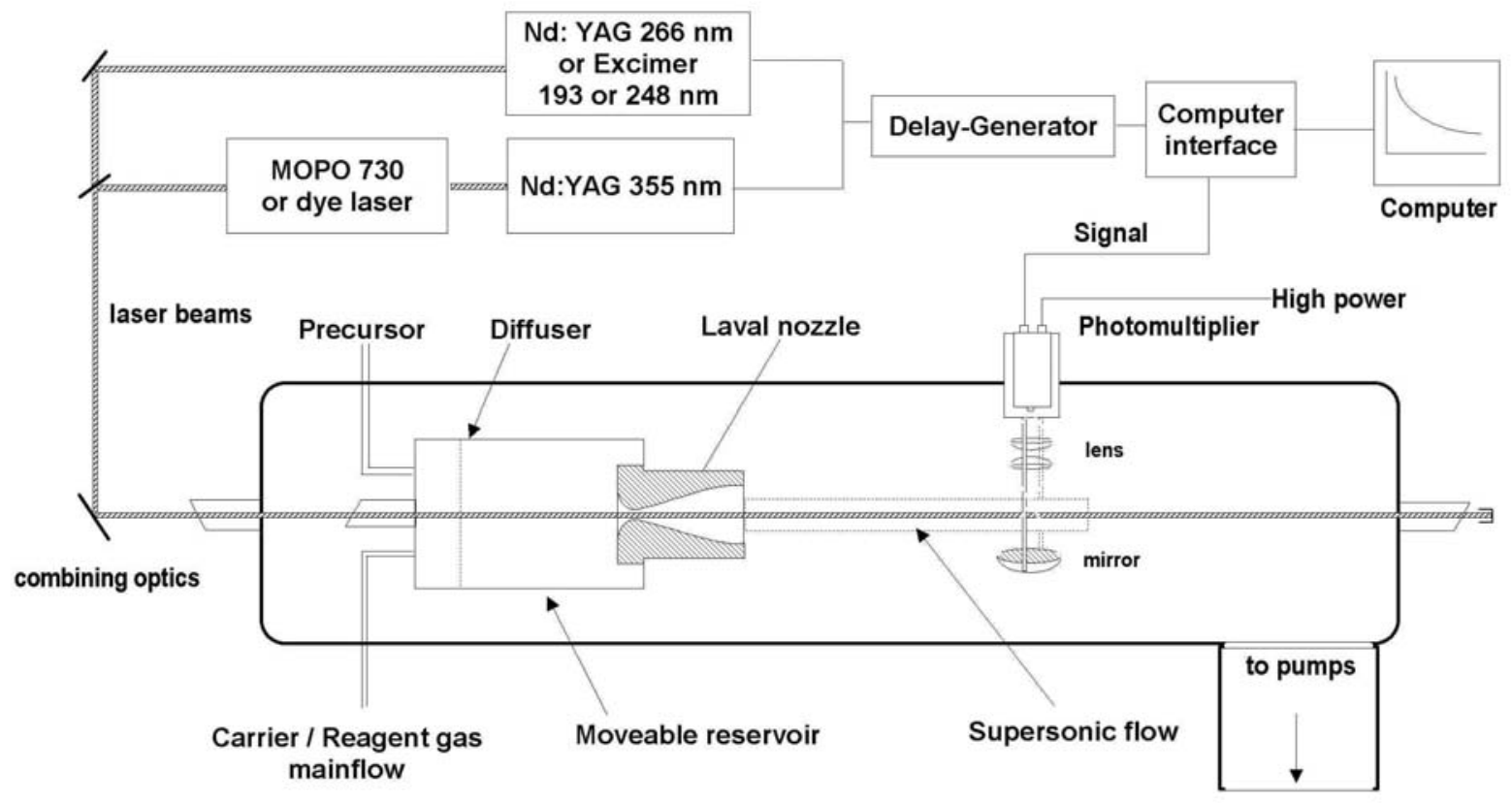

\section{The Crossed Molecular Beam Technique with Mass Spectrometric Detection}

Amongst the possible experimental techniques to study a bimolecular reaction under collision-free conditions, the most versatile one is the crossed molecular beam (CMB) technique with massspectrometric (MS) detection. This technique was first developed in the late ' 60 s and used to address fundamental aspects of the reaction mechanisms at the microscopic level [56], while only recently, improvements in the production of beams of unstable species and vacuum technology have allowed the study of elementary reactions of interest in astrochemistry [31,84-135]. The main advantage of CMB experiments is that the reactants are confined into distinct supersonic beams which cross each other at a specific angle; the species of each beam are characterized by a well defined (both in magnitude and direction) velocity and are made to collide only with the molecules of the other beam, allowing us to observe the consequences of well defined molecular collisions. The products are formed at the collision center and then fly undisturbed towards the detector because of the large mean free path achieved by operating at a very low pressure $\left(10^{-5} \mathrm{~Pa}\right)$. In CMB experiments the product detection can be done by means of spectroscopic techniques or mass-spectrometry. Even though notable examples of CMB experiments coupled to spectroscopic detection on reactions of relevance in astrochemistry are available in the literature [61,121-123,134], the use of MS detection is especially advantageous compared to spectroscopic techniques, the applicability of which requires the knowledge of the optical properties of the products - while, in many cases, their nature itself is unknown. The coupling with MS detection, in fact, makes the method universal, that is, applicable to the study of (at least in 
principle) any reaction [56]. Every species can be ionized at the electron energy typically used in the ionizer $(\geq 70 \mathrm{eV})$ which precedes the mass filter. Therefore, it is possible to determine the mass (and, in favorable cases, the gross formula) of all possible species produced from the reactions by ionizing the product and selecting different mass-to-charge ratios $(\mathrm{m} / \mathrm{z})$ in the mass selector. Some problems, such as dissociative ionization and background noise, have restricted the sensitivity of the method, but the recent implementation of the soft electron ionization (EI) approach has partly overcome this problem $[113,114,127,128]$. To be noted that an important advantage with respect to common MS flow reactors is the possibility to measure product angular and velocity distributions, which allows one to directly derive the amount of the total energy available to the products and, therefore, the energetics of the reaction. This is crucial when more isomers with the same gross formula can be produced [117]. In general, the CMB technique allows one to determine (a) the nature of the primary reaction products, (b) the branching ratios of competing reaction channels, (c) the microscopic reaction mechanisms $(d)$ the product energy partitioning. More generally, we can say that it is possible to obtain information on the underlying potential energy surfaces (PES) governing the transformation from reactants to products.

The benefits of the CMB technique strongly motivate its extension to the study of reactions of interest in astrochemistry. In the last few years the CMB method with MS detection has indeed been applied to the study of astronomically relevant reactions in different laboratories, especially in the research groups of Kaiser [31,84-112,135] and Casavecchia [113-133]. CMB machines equipped with MS detection can vary to some extent depending on the way used to generate the unstable species beams. On the one hand, we have laser-based generation techniques, amongst which laser photolysis [135] or laser induced ablation from a refractory material rod and, eventually, subsequent reaction of the ablated species with another gas [136]. This method has been widely used in the laboratory of Kaiser to produce pulsed supersonic beams of atoms or radicals, such as $\mathrm{C}$ and $\mathrm{B}$ atoms, $\mathrm{CN}$ and $\mathrm{C}_{2} \mathrm{H}$ radicals, $\mathrm{C}_{2}$ and $\mathrm{C}_{3}[31,87,91,94]$. Alternatively, beams of unstable species can be produced by flash pyrolysis or electrical discharge. A pulsed pyrolytic source has been used by Kaiser and coworkers to produce beams of $\mathrm{C}_{3} \mathrm{H}_{5}$ and $\mathrm{C}_{6} \mathrm{H}_{5}$ radicals [137,138], while a continuous pyrolytic source has been used by Casavecchia and coworkers to produce beams of $\mathrm{C}_{3} \mathrm{H}_{5}$ and $\mathrm{CH}_{3}[113,139]$. A radiofrequency discharge beam source has been widely used by Casavecchia and coworkers to produce beams of $\mathrm{C}, \mathrm{O}$, $\mathrm{N}, \mathrm{S}, \mathrm{Cl}$ atoms, $\mathrm{OH}$ and $\mathrm{CN}$ radicals and $\mathrm{C}_{2}[140]$.

An important, recent achievement in the crossed molecular beam machine with MS detection of Casavecchia is the set-up of a variable beam crossing angle configuration [113,114], see Figure 2 . The relative collision energy, $\mathrm{E}_{\mathrm{c}}$, in a CMB experiment is given by $1 / 2 \mu \mathrm{v}_{\mathrm{r}}^{2}$, where $\mu$ is the reduced mass of the system and $v_{r}$ is the relative velocity. In general $v_{r}$ is given by the equation $v_{r}^{2}=v_{1}^{2}+v_{2}^{2}-$ $2 v_{1} v_{2} \cos \gamma$, where $v_{1}$ and $v_{2}$ are the two reactant beam velocities in the laboratory frame and $\gamma$ is the crossing angle of the two beams. Traditionally, CMB instruments with MS detection have featured a beam crossing angle $\gamma$ of $90^{\circ}$. In apparatuses with fixed $\gamma=90^{\circ}$, the $\mathrm{E}_{\mathrm{c}} \mathrm{s}$ achievable are limited by the velocities with which the two beams can be produced. The relatively high $\mathrm{E}_{\mathrm{c}} \mathrm{s}$ normally achieved in $\mathrm{CMB}$ experiments might affect the results obtained by this technique on astronomically relevant reactions if there is a change of the reaction mechanism with varying $\mathrm{E}_{\mathrm{c}}$. To overcome this problem, a variable beam crossing angle set-up, which allows crossing of the two reactant beams at three different angles of $45^{\circ}, 90^{\circ}$, and $135^{\circ}$ has been implemented. With this new setting, $\mathrm{E}_{\mathrm{c}}$ could be varied over a 
much wider range than previously possible: with the beam velocities remaining constant, the $\gamma=135^{\circ}$ configuration allows reaching higher $E_{c}$ while the $\gamma=45^{\circ}$ arrangement is intended for reaching very low $\mathrm{E}_{\mathrm{c}}$. In this way, the bimolecular reactions can be studied under collision free conditions at collision energies that resemble those of relevance in astrochemistry with typical environments at low $\mathrm{T}$.

Another important achievement obtained in the group of Casavecchia is the implementation of softEI by means of a tunable ionizer [113,114]. In this way, by tuning the electron energy below the threshold for dissociative ionization of interfering species, it is possible to eliminate or reduce the background or interfering signal of different sources [125,127,128] that, in several cases, would prohibit the reactive scattering experiments. Remarkably, the use of a tunable electron impact ionizer in the $\mathrm{CMB}$ instrument permits measuring the EI efficiency curves of the reaction products as a function of electron energy down to their ionization thresholds and, from these, obtaining a direct estimate of the ionization energy of the product radicals [132]. In other words, it is possible to measure the unknown ionization energy of radical species by 'synthesizing' them in CMB reactive scattering experiments.

Figure 2. Schematic view of the Perugia crossed molecular beam apparatus (lhs). The three possible crossing beam geometries are also shown on the right-hand-side. Adapted with permission from reference [113].
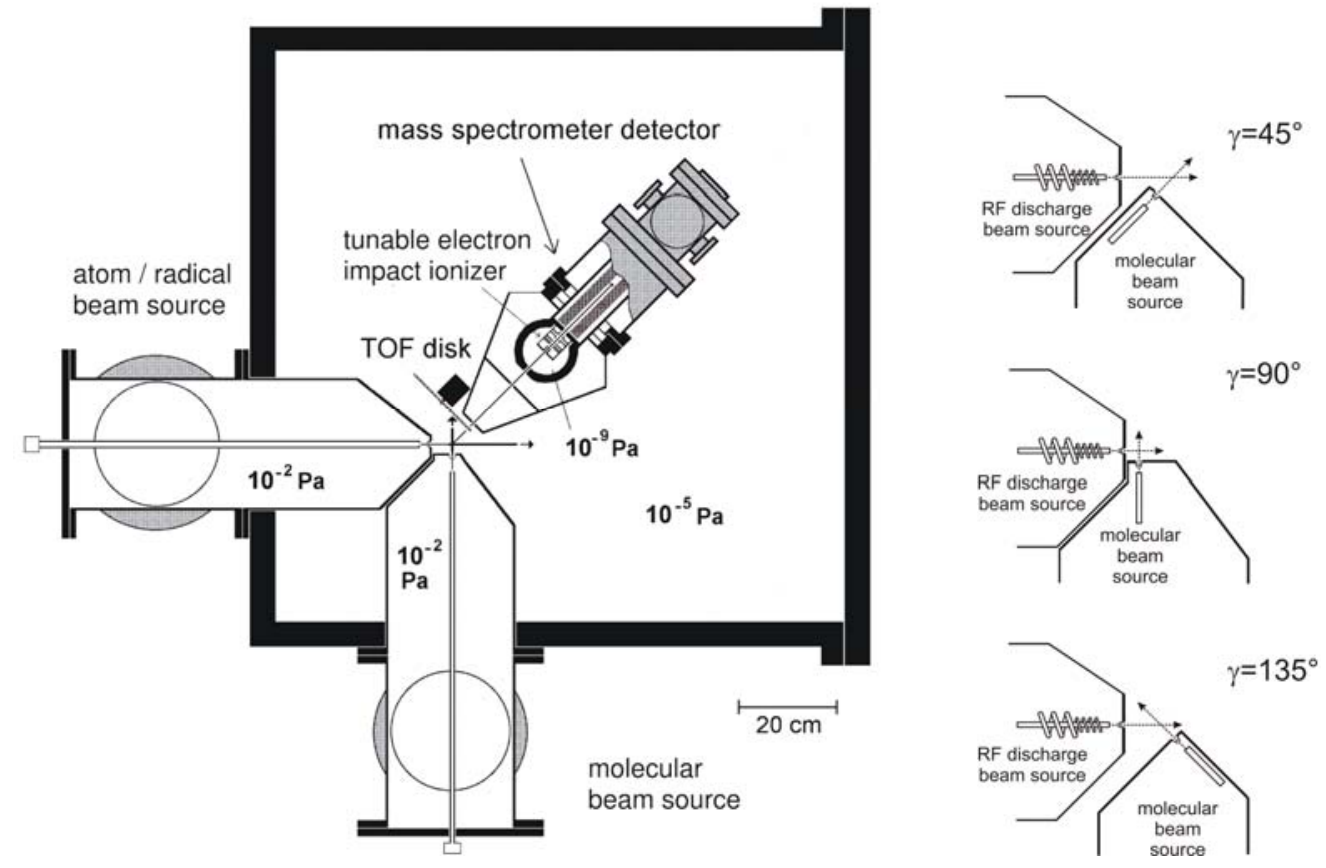

\section{Key Results on the Reactions of CN Radicals}

Cyanopolyynes, with the general chemical formula $\mathrm{H}-(\mathrm{C} \equiv \mathrm{C})_{\mathrm{n}}-\mathrm{CN}$, are ubiquitous in the ISCs and displzy high fractional abundances of up to $6 \times 10^{-9}$ [141]. The simplest one, cyanoacetylene $\operatorname{HCCCN}\left(\mathrm{X}^{1} \Sigma^{+}\right)$, has been identified in the dark molecular clouds TMC-1 and OCM-1 as well as the carbon star IRC $+10,216(\mathrm{CW}$ Leo), towards high intensity IR sources (IRC $+10,216)$ and massive $\mathrm{O}-\mathrm{B}$ stars within dense molecular clouds [142-144]. More complex cyanopolyynes up to $\mathrm{HC}_{11} \mathrm{~N}$ have 
been assigned in TMC-1 [145,146]. Methylcyanoacetylene, $\mathrm{CH}_{3} \mathrm{CCCN}$ [147], vinylcyanide, $\mathrm{C}_{2} \mathrm{H}_{3} \mathrm{CN}$, [148] and the two radicals $\mathrm{C}_{3} \mathrm{~N}$ and $\mathrm{C}_{5} \mathrm{~N}[149,150]$ have also been identified in various objects. Early models of ISC chemistry suggested that the dissociative recombination of the $\mathrm{HCCCNH}^{+}$ion was the main formation mechanism of $\mathrm{HCCCN}$ and its isomer $\mathrm{HCCNC}$. The ion $\mathrm{HCCCNH}^{+}$was assumed to be formed via ion-molecule reactions, amongst which $\mathrm{N}\left({ }^{4} \mathrm{~S}\right)+\mathrm{C}_{3} \mathrm{H}_{3}{ }^{+}$. Nevertheless, this $\mathrm{HCCCN}$ formation route cannot explain either the observed [HCCCN]:[HCCNC]:[HNCCC] ratio or the $\mathrm{HCCCN}$ isotopomers $\left(\mathrm{H}^{13} \mathrm{CCCN}, \mathrm{HC}^{13} \mathrm{CCN}, \mathrm{HCCC}^{13} \mathrm{CN}\right)$ abundance towards TMC-1. Finally, a recent theoretical investigation of the possible ion-molecule reactions leading to $\mathrm{HCCCNH}^{+}$showed that they are not feasible in molecular clouds [151].

Therefore, neutral-neutral reactions, based on the generalization of the reaction scheme:

$$
\mathrm{CN}\left(\mathrm{X}^{2} \Sigma^{+}\right)+\mathrm{H}-(\mathrm{C} \equiv \mathrm{C})_{\mathrm{n}}-\mathrm{H} \rightarrow \mathrm{H}-(\mathrm{C} \equiv \mathrm{C})_{\mathrm{n}}-\mathrm{CN}+\mathrm{H}\left({ }^{2} \mathrm{~S}_{1 / 2}\right) \quad(\mathrm{n}=1,2, . .)
$$

have been proposed (see [152-154] and references therein).

Cyanoacetylene has also been observed in the atmosphere of Titan, together with other CN containing molecules, such as $\mathrm{HCN}, \mathrm{C}_{2} \mathrm{~N}_{2}$ and $\mathrm{CH}_{3} \mathrm{CN}$ [155-157]. Even though they occur only in trace amounts of a few parts per billion, they are of particular importance because they are thought to be the key intermediates to the formation of biologically relevant molecules. Nitriles can be hydrolyzed and react via multistep synthesis ultimately to amino acids, thus providing one of the basic "ingredients" for life. In the upper layers of Titan's atmosphere, the energy deposition is mainly from high-energy electrons from Saturn's magnetosphere and short-wavelength solar ultraviolet photons $(\lambda<155 \mathrm{~nm})$. Longer wavelength photons penetrate down to the stratosphere and photodissociate $\mathrm{HCN}$ to cyano radicals, $\mathrm{CN}\left(\mathrm{X}^{2} \Sigma^{+}\right)$. The cyano radical concentration profile overlaps with that of acetylene, so that their reaction is a plausible route of formation of cyanoacetylene.

Certainly the possible importance of $\mathrm{CN}$ radical reactions with the hydrocarbons widely spread in ISCs and Titan's atmosphere became obvious after the CRESU results on these reactive systems. All the reactions with the abundant unsaturated hydrocarbons acetylene, methylacetylene, allene and ethylene $[67,158]$ have been found to be very fast, within the gas kinetic limit, down to very low temperatures (as low as $25 \mathrm{~K}$ ). More surprisingly, the reaction $\mathrm{CN}+\mathrm{C}_{2} \mathrm{H}_{6}$, the rate constant of which decreases with decreasing temperature up to $\sim 100 \mathrm{~K}$, was found to become faster at temperatures below $75 \mathrm{~K}$ and the rate constant reaches the value of $1.1 \times 10^{-10} \mathrm{~cm}^{3} \mathrm{molec}^{-1} \mathrm{~s}^{-1}$ at $25 \mathrm{~K}$. The temperature dependence of the reaction $\mathrm{CN}+\mathrm{C}_{2} \mathrm{H}_{6}$, see Figure 3, is probably the best example to demonstrate how the extrapolation at low temperatures of the rate constant outside the range of temperature investigated can be misleading. Recent theoretical calculations have been able to account for such a peculiar behavior [159]. After the CRESU experiments provided evidence that cyano radicals easily react also at the temperatures of Titan and ISM with relatively abundant hydrocarbons, only one parameter remained to be checked: the nature and the yield of the reaction products.

By combining CMB-MS experiments with the electronic structure calculations of the relevant stationary points along the minimum energy path, Kaiser and coworkers [84-87,98] have been able to demonstrate that $\mathrm{HCCCN}+\mathrm{H}$ is the only open channel for the reaction $\mathrm{CN}+\mathrm{C}_{2} \mathrm{H}_{2}$ (2), thus providing an experimental confirmation of the reaction scheme (1). Also, with the same technique the reactions $\mathrm{CN}+\mathrm{C}_{2} \mathrm{H}_{4}$ (3) [97], $\mathrm{CN}+\mathrm{CH}_{3} \mathrm{CCH}$ (4) [96,101], $\mathrm{CN}+\mathrm{CH}_{2}=\mathrm{C}=\mathrm{CH}_{2}$ (5) [96], $\mathrm{CN}+\mathrm{CH}_{3} \mathrm{CCCH}_{3}$ (6) [100], $\mathrm{CN}+\mathrm{C}_{6} \mathrm{H}_{6}$ (7) [99] and $\mathrm{CN}+\mathrm{CH}_{3} \mathrm{CH}=\mathrm{CH}_{2}$ (8) [95] have been investigated. All of them share a 
similar reaction mechanism: the electrophilic $\mathrm{CN}$ radical interacts with the $\pi$ electrons of the multiple bond of the unsaturated hydrocarbon without an entrance barrier, leading to the formation of a relatively stable addition intermediate. Because of its high energy content, the addition intermediate can directly undergo a $\mathrm{C}-\mathrm{H}$ bond cleavage or isomerize to other intermediates before fragmenting into products. In this way, the identified molecular products were: cyanoacetylene, HCCCN, from the reaction $\mathrm{CN}+\mathrm{C}_{2} \mathrm{H}_{2}$, vinylcyanide from the reaction $\mathrm{CN}+\mathrm{C}_{2} \mathrm{H}_{4}$, cyanomethylacetylene, $\mathrm{CH}_{3} \mathrm{CCCN}$, and cyanoallene, $\mathrm{CH}_{2} \mathrm{CCH}(\mathrm{CN})$, from the reaction $\mathrm{CN}+\mathrm{CH}_{3} \mathrm{CCH}$, cyanoallene and 3-cyanomethylacetylene from the reaction $\mathrm{CN}+\mathrm{CH}_{2}=\mathrm{C}=\mathrm{CH}_{2}, \mathrm{CH}_{2} \mathrm{CCCN}\left(\mathrm{CH}_{3}\right)$ and $\mathrm{CH}_{3} \mathrm{CCCN}$ from the reaction $\mathrm{CN}$ $+\mathrm{CH}_{3} \mathrm{CCCH}_{3}$, cyanobenzene from the reaction $\mathrm{CN}+\mathrm{C}_{6} \mathrm{H}_{6}$ and $\mathrm{CH}_{2}=\mathrm{CHCH}_{2} \mathrm{CN}$ and $\mathrm{CH}_{3} \mathrm{CH}=\mathrm{CHCN}$ from the reaction $\mathrm{CN}+\mathrm{CH}_{3} \mathrm{CH}=\mathrm{CH}_{2}$. The results obtained for reaction (2) have been confirmed by another CMB-MS study [117].

Figure 3. Rate coefficients for the reaction $\mathrm{CN}+\mathrm{C}_{2} \mathrm{H}_{6}$ as a function of temperature, displayed on a log-log scale. The filled circles represent the results obtained in the CRESU experiment of Reference [67], open triangles are from Reference [163] while the open circles are from cooled cell experiments of Reference [67]. Adapted from Canosa, A.; Goulay, F.; Sims, I.R.; Rowe, B.R. Gas phase reactive collisions at very low temperature: recent experimental advances and perspectives. In Low Temperatures and cold molecules, Copyright 2008, published with permission from World Scientific Publishing Co. Pte. Ltd, Singapore.

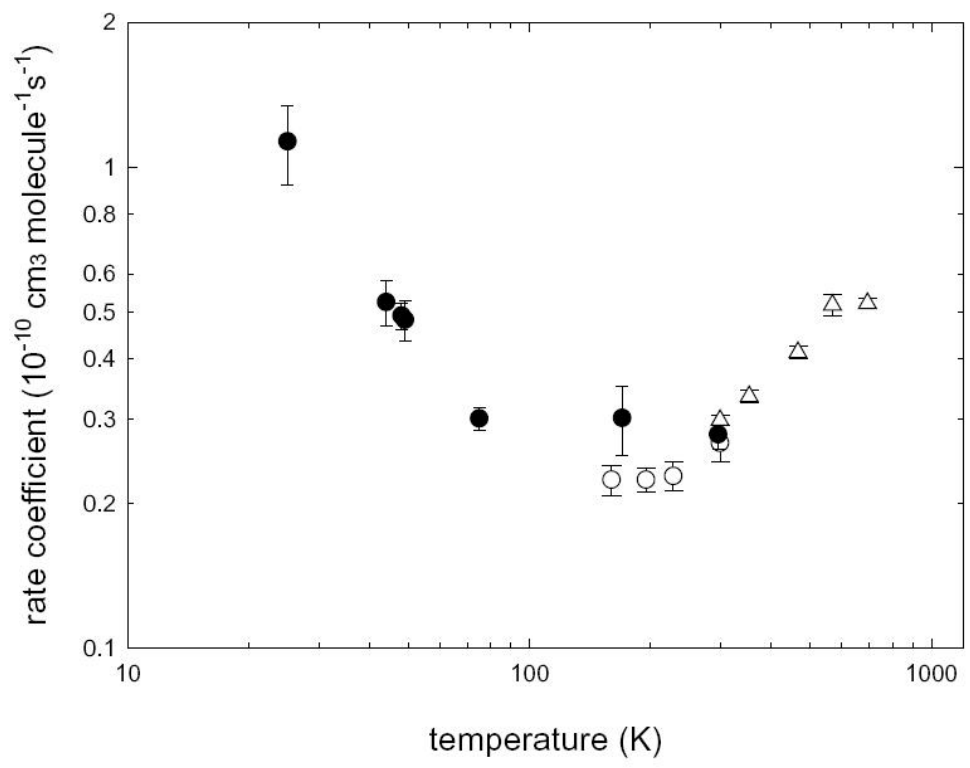

For the cases (2) and (3) the dominance of the H-displacement channel, leading to the molecular products listed above, has been confirmed by recent kinetic measurements where the $\mathrm{H}$ growth was monitored [160,161], while for the reaction of $\mathrm{CN}$ with propene (8) other reaction channels are open [161]. Finally, very recent experimental results obtained by the novel multiplexed time-resolved mass spectrometry with tunable synchrotron photoionization technique [162] have confirmed that $\mathrm{C}_{2} \mathrm{H}_{3} \mathrm{CN}$ is the sole molecular product from reaction (3), while in the case of reaction (8) the channel leading to $\mathrm{C}_{2} \mathrm{H}_{3} \mathrm{CN}+\mathrm{CH}_{3}$ is the dominant one $(75 \pm 15 \%)$, with the minor $\mathrm{H}$-displacement channel producing the 
isomers 1-cyanopropene (57 $\pm 15 \%)$, 2-cyanopropene (43 $\pm 15 \%)$ and 3-cyanopropene $(<15 \%)$ [162]. In all reactions discussed above, the formation of isonitriles is never favored because all the reaction channels leading to these isomers are either endothermic by a few $\mathrm{kJ} \mathrm{mol}^{-1}$ or the relative exit barriers are $5-30 \mathrm{kJmol}^{-1}$ above the energy of the separated reactants [84]. In some cases, the theoretical calculations show that the formation of $\mathrm{HCN}$ and an alkyl radical is a possible reaction channel, but HCN has never been observed, not even in the case of reaction (8) [162].

In summary, in all the reactions investigated the $\mathrm{CN} / \mathrm{H}$ exchange channel is a main reaction pathway and products with a multiple $\mathrm{C}-\mathrm{C}$ bond and a $-\mathrm{CN}$ group are formed. The structures of the products are reported in Figure 4. Furthermore, these reactions are also very fast at very low temperatures and therefore they represent a viable route for the formation of complex nitriles in the ISCs and cold planetary atmospheres, provided that the precursor molecules (HCN and unsaturated hydrocarbons) are present. In this respect, a nice example of how the results of CMB experiments can assist the astronomical search for hitherto unobserved molecules is furnished by the detection of cyanoallene towards the dark Taurus molecular cloud (TMC-1) [164,165]. Since both cyanomethylacetylene and cyanoallene are produced from the reaction between cyano radical and methylacetylene, if the reaction (4) is the source of methylacetylene in ISCs it is reasonable to expect the presence of cyanoallene as well. And this is in fact the case [164,165].

Figure 4. Closed-shell unsaturated nitriles observed as molecular products in the reactions between cyano radicals and unsaturated hydrocarbons.<smiles>C#CC#N</smiles><smiles>C=CC#N</smiles><smiles>C#CCC#N</smiles><smiles>C=CCC#N</smiles><smiles>C=C=C(C)C#N</smiles><smiles>CC#CC#N</smiles><smiles>C=C=CC#N</smiles><smiles>C/C=C\C#N</smiles><smiles>C/C=C\C#N</smiles>

There is some interest also in the reaction of $\mathrm{CN}$ with saturated hydrocarbons. In particular, the reaction with methane, the most abundant hydrocarbon in the atmosphere of Titan, $\mathrm{CN}+\mathrm{CH}_{4}(9)$, was invoked to account for the formation of acetonitrile in the atmosphere of Titan [43], according to the scheme $\mathrm{CN}+\mathrm{CH}_{4} \rightarrow \mathrm{CH}_{3} \mathrm{CN}+\mathrm{H}$. This reaction is not as fast as those with unsaturated hydrocarbons and is characterized by a room temperature rate constant of $5.95 \times 10^{-13}$ molec $\mathrm{cm}^{-3} \mathrm{~s}^{-1}$ [67]. An attempt to measure the $\mathrm{H}$ product yield was pursued by Gannon et al. [161], who were not able to observe any growth in $\mathrm{H}$ atom production matching the kinetics of $\mathrm{CN}$ removal. The main reaction channel is therefore the one leading to $\mathrm{HCN}+\mathrm{CH}_{3}$. An upper limit of $5 \%$ of yield for the channel 
leading to acetonitrile $+\mathrm{H}$ was given, but it was attributed to the background noise. Recent experiments by using the crossed-beam dc slice imaging [134] have been able to characterize the reaction mechanism of several reactions involving $\mathrm{CN}$ radicals and alkanes leading to alkyl radical $+\mathrm{HCN}$.

\section{Key Results on the Reactions of $\mathrm{C}_{2}$}

$\mathrm{C}_{2}$ is one of the simplest diatomic molecules, but, in contrast to the similar $\mathrm{N}_{2}$ or $\mathrm{O}_{2}$ molecules, it is highly reactive. Another peculiarity of $\mathrm{C}_{2}$ is that the first electronically excited metastable state $\left(a^{3} \Pi_{\mathrm{u}}\right)$ lies only $610 \mathrm{~cm}^{-1}$ (or $7.3 \mathrm{~kJ} \mathrm{~mol}^{-1}$ ) above the ground state $\left(X^{1} \Sigma_{\mathrm{g}}^{+}\right.$). $\mathrm{C}_{2}$ has been identified in the interstellar medium (see for instance [166]) and cometary comae (see for instance [167-169]), while its detection in planetary atmospheres has never been reported in the literature. Nevertheless, formation and destruction processes of $\mathrm{C}_{2}$ are included in the photochemical models of planetary atmospheres where $\mathrm{C}_{2} \mathrm{H}_{2}$ has been observed [27,37-45,47,48], since $\mathrm{C}_{2}$ is expected to be produced (directly or in two steps) by acetylene photodissociation. Because of the very low energy content of the $\mathrm{a}^{3} \Pi_{\mathrm{u}}$ excited state, which can be produced by $\mathrm{C}_{2} \mathrm{H}$ photodissociation [170], the presence of $\mathrm{C}_{2}\left(a^{3} \Pi_{\mathrm{u}}\right)$ in various environments cannot be ruled out and its chemistry should be considered as well. Several experimental studies have been carried out to measure the rate coefficients of the removal of $\mathrm{C}_{2}\left(\mathrm{a}^{3} \Pi_{\mathrm{u}}\right)$ and $\mathrm{C}_{2}\left(X^{1} \Sigma_{\mathrm{g}}^{+}\right)$ by hydrocarbons at room or higher temperature [171-174] and the results obtained for the reactions $\mathrm{C}_{2}\left(X^{1} \Sigma_{\mathrm{g}}^{+}\right)+\mathrm{H}_{2}$ and $\mathrm{C}_{2}\left(X^{1} \Sigma_{\mathrm{g}}^{+}\right)+\mathrm{CH}_{4}$ have been used in several photochemical models, after the extrapolation of the given rate coefficient temperature dependences to the conditions pertinent to planetary atmospheres. As already pointed out, such an extrapolation is not warranted. In the most recent model on the atmosphere of Titan by Lavvas et al. $[47,48]$ the reactions of $\mathrm{C}_{2}\left(X^{1} \Sigma_{\mathrm{g}}^{+}\right)$with several hydrocarbons (including acetylene) have been included with the rate constants measured at 300 $\mathrm{K}$. Recent CRESU kinetic experiments in the temperature range between 24 and $300 \mathrm{~K}$ [71,72] on several reactions of ${ }^{1} \mathrm{C}_{2}$ have now furnished the correct temperature dependence for the reactions $\mathrm{C}_{2}\left(X^{1} \Sigma_{\mathrm{g}}^{+}\right)+\mathrm{H}_{2}$ and $\mathrm{C}_{2}\left(X^{1} \Sigma_{\mathrm{g}}^{+}\right)+\mathrm{CH}_{4}$, and also for other reactions with simple hydrocarbons. Remarkably, those studies have demonstrated that the reactivity of $\mathrm{C}_{2}\left(X^{1} \Sigma^{+} \mathrm{g}\right)$ with simple saturated $\left(\mathrm{C}_{2} \mathrm{H}_{6}\right.$ and $\left.\mathrm{C}_{3} \mathrm{H}_{8}\right)$ and unsaturated $\left(\mathrm{C}_{2} \mathrm{H}_{2}\right.$ and $\left.\mathrm{C}_{2} \mathrm{H}_{4}\right)$ hydrocarbons is very high with rate constants in the gas kinetics range. According to these new experimental results it has been established that [71]: (a) the reaction $\mathrm{C}_{2}\left(X^{1} \Sigma_{\mathrm{g}}^{+}\right)+\mathrm{CH}_{4}$ is more efficient at low temperatures than what could be estimated by extrapolating the high temperature rate coefficients of Pitts et al. [173] (2) since the rate constants for the reactions $\mathrm{C}_{2}\left(X^{1} \Sigma_{\mathrm{g}}^{+}\right)+\mathrm{C}_{2} \mathrm{H}_{2}$ and $\mathrm{C}_{2}\left(X^{1} \Sigma_{\mathrm{g}}^{+}\right)+\mathrm{C}_{2} \mathrm{H}_{4}$ are larger than estimated, they should be included in the photochemical models of Titan, whereas the reaction of $\mathrm{C}_{2}\left(X^{1} \Sigma_{\mathrm{g}}^{+}\right)$with $\mathrm{H}_{2}$ (presently included) actually has a negligible impact; (3) in the atmospheres of Saturn and Uranus, the reactions $\mathrm{C}_{2}\left(X^{1} \Sigma_{\mathrm{g}}^{+}\right)+\mathrm{C}_{2} \mathrm{H}_{2}$ and $\mathrm{C}_{2}\left(X^{1} \Sigma_{\mathrm{g}}^{+}\right)+\mathrm{C}_{2} \mathrm{H}_{6}$ should be included in the models. More recent results on $\mathrm{C}_{2}\left(X^{1} \Sigma_{\mathrm{g}}^{+}\right)+\mathrm{C}_{2} \mathrm{H}_{2}$ obtained by Daugey et al. [175] using another CRESU apparatus at temperatures as low as $77 \mathrm{~K}$ confirm the results by Canosa et al. [71]. Also the kinetics involving $\mathrm{C}_{2}$ in the triplet $a^{3} \Pi_{\mathrm{u}}$ state have been characterized with the CRESU technique [72]. Even though the trend with the temperature was quite different with respect to that of the singlet reaction, the rate constants for the reactions of $\mathrm{C}_{2}\left(a^{3} \Pi_{\mathrm{u}}\right)$ with $\mathrm{C}_{2} \mathrm{H}_{2}$ and other unsaturated hydrocarbons are relatively large. In 
conclusion, the CRESU experiments point to an efficient removal of both $\mathrm{C}_{2}\left(X^{1} \Sigma_{\mathrm{g}}^{+}\right)$and $\mathrm{C}_{2}\left(a^{3} \Pi_{\mathrm{u}}\right)$ by acetylene (and other hydrocarbons) at the temperatures of relevance to Titan, Giant Planets and ISCs.

As far as the nature of the reaction products is concerned, a systematic investigation by the CMBMS technique has been pursued by Kaiser and co-workers [88-94] for these reactions as well and quite interesting results have been obtained. For instance, it has been demonstrated that the products of the $\mathrm{C}_{2}+\mathrm{C}_{2} \mathrm{H}_{4}$ reaction are not $\mathrm{C}_{2} \mathrm{H}+\mathrm{C}_{2} \mathrm{H}_{3}$ or $\mathrm{C}_{2} \mathrm{H}_{2}+\mathrm{C}_{2} \mathrm{H}_{2}$, as previously assumed, but $n-\mathrm{C}_{4} \mathrm{H}_{3}+\mathrm{H}$ [92], that is, the $\mathrm{C}_{2}+\mathrm{C}_{2} \mathrm{H}_{4}$ reaction leads to a carbon chain elongation. Similarly, $\mathrm{C}_{4} \mathrm{H}$ has been identified as the primary product of the $\mathrm{C}_{2}+\mathrm{C}_{2} \mathrm{H}_{2}$ reaction, leading again to a carbon chain elongation [89,90]. Also, the 2,4-pentadiynyl-1 radical, $\mathrm{HCCCCCH}_{2}$, is the main product of the reaction $\mathrm{C}_{2}+\mathrm{CH}_{3} \mathrm{CCH}$ [93], while the 1,3,5-hexatriynyl radical, $\mathrm{C}_{6} \mathrm{H}$, is the main product of the reaction $\mathrm{C}_{2}+\mathrm{C}_{4} \mathrm{H}_{2}$ (diacetylene) [88]. In all cases a carbon chain elongation was observed.

The reaction $\mathrm{C}_{2}+\mathrm{C}_{2} \mathrm{H}_{2}$ has also been investigated by Casavecchia and co-workers $[125,126]$. In this more recent study, the $\mathrm{C}_{2}$ internal state population has been characterized by laser induced fluorescence to assist the interpretation of the reactive scattering results [125]. In spite of some differences in the characterization of the reaction mechanism, the results by Casavecchia and coworkers confirmed that $\mathrm{C}_{4} \mathrm{H}+\mathrm{H}$ is the main reaction channel $[125,126]$ and that $\mathrm{C}_{2}$ reactions with unsaturated hydrocarbons can be a viable route to synthesize polyynes in the interstellar medium.

\section{Key Results on the Reactions of Atomic Nitrogen, $N\left({ }^{2} D\right)$}

The atmosphere of Titan is a gaseous environment dominated by molecular nitrogen and methane. In this condition, it is intuitive that the formation of nitriles is initiated by the reactions of active forms of nitrogen - such as nitrogen atoms or ions, which can be formed in the upper atmosphere from the abundant parent molecule $\mathrm{N}_{2}$. In particular, atomic nitrogen can be produced by $\mathrm{N}_{2}$ dissociation induced by electron impact, extreme ultra-violet photolysis and dissociative photoionization, galactic cosmic ray absorption, and $\mathrm{N}_{2}{ }^{+}$dissociative recombination. These processes lead to atomic nitrogen in the ground, ${ }^{4} \mathrm{~S}_{3 / 2}$, and first electronically excited, ${ }^{2} \mathrm{D}_{3 / 2,5 / 2}$, states with comparable yields. The radiative lifetimes of the metastable states ${ }^{2} \mathrm{D}_{3 / 2}$ and ${ }^{2} \mathrm{D}_{5 / 2}$ are quite long (12.3 and 48 hours, respectively), because the transition from a doublet to a quartet state is strongly forbidden. In addition, collisional deactivation of $\mathrm{N}\left({ }^{2} \mathrm{D}\right)$ by $\mathrm{N}_{2}$ is a slow process [176] and, therefore, the main fate of $\mathrm{N}\left({ }^{2} \mathrm{D}\right)$ above $800 \mathrm{~km}$ is chemical reaction with other constituents of Titan's atmosphere. The production of $\mathrm{N}$ atoms in the ${ }^{2} \mathrm{D}$ state is an important fact, because $\mathrm{N}\left({ }^{4} \mathrm{~S}\right)$ atoms exhibit very low reactivity with closed-shell molecules and the probability of collision with an open-shell radical is small. On the contrary the reactions of $\mathrm{N}\left({ }^{2} \mathrm{D}\right)$ with several molecules identified in the atmosphere of Titan (including the relatively abundant $\mathrm{CH}_{4}$ and $\mathrm{H}_{2}$ ) can make an important contribution to the chemical evolution of the atmosphere. Yung et al. [41] suggested that the main products of the $\mathrm{N}\left({ }^{2} \mathrm{D}\right)+\mathrm{CH}_{4}(10)$ reaction are $\mathrm{NH}$ and $\mathrm{CH}_{3}$ and, on this assumption, drew some reaction cycles, which ultimately lead to the formation of $\mathrm{HCN}$. Also, Yung [177] suggested that the reaction $\mathrm{N}\left({ }^{2} \mathrm{D}\right)+\mathrm{C}_{2} \mathrm{H}_{2}$ (11) can be responsible for cyanogen, $\mathrm{C}_{2} \mathrm{~N}_{2}$, and $\mathrm{C}_{4} \mathrm{~N}_{2}$ formation in the case it produces $\mathrm{HCCN}+\mathrm{H}$. More recent photochemical models for calculating the vertical distribution of Titan's neutral atmosphere compounds rely on a similar suggestion $[45,48]$. 
Accurate laboratory experiments on the $\mathrm{N}\left({ }^{2} \mathrm{D}\right)$ reactions have become available only in the late 1990 s, because of the experimental difficulties in studying those systems. The room temperature rate constants for reactions (10) and (11) have been found to be slightly larger than those used in the models [176]. As far as reaction (10) is concerned, however, the results of recent reaction dynamics studies do not confirm the assumptions of Yung about the reaction mechanism and the nature of the products. According to the $a b$ initio calculations of the $\mathrm{NCH}_{4} \mathrm{PES}$ [178], the possible products are (10a) $\mathrm{CH}_{3} \mathrm{~N}+\mathrm{H},(10 \mathrm{~b}) \mathrm{NH}+\mathrm{CH}_{3},(10 \mathrm{c}) \mathrm{CHNH}_{2}+\mathrm{H}$, and (10d) $\mathrm{CH}_{2} \mathrm{NH}+\mathrm{H}$. A recent spectroscopic study under collision-free conditions [179] derived an absolute yield of $0.3 \pm 0.1$ for $\mathrm{NH}$ (from channel $10 \mathrm{~b}$ ) and $0.8 \pm 0.2$ for $\mathrm{H}$ (from channels $10 \mathrm{a}, 10 \mathrm{c}, 10 \mathrm{~d}$ ) production. The nature of the $\mathrm{CH}_{3} \mathrm{~N}$ isomer(s) produced in conjunction with $\mathrm{H}$ has been established in a CMB-MS study of the $\mathrm{N}\left({ }^{2} \mathrm{D}\right)+\mathrm{CH}_{4}$ reaction as a function of collision energy (from $\sim 20 \mathrm{~kJ} \mathrm{~mol}^{-1}$ to $\sim 60 \mathrm{~kJ} \mathrm{~mol}^{-1}$ ) [117-119,180]. Interestingly, the channels leading to $\mathrm{CH}_{2} \mathrm{NH}$ (methanimine) and $\mathrm{CH}_{3} \mathrm{~N}$ (methylnitrene) were found to be both open and the relative branching ratio, $\sigma\left(\mathrm{CH}_{2} \mathrm{NH}+\mathrm{H}\right) / \sigma\left(\mathrm{CH}_{3} \mathrm{~N}+\mathrm{H}\right)$, was found to vary considerably with the amount of energy available [119]. In Figure 5 we report the results obtained at $\mathrm{E}_{\mathrm{c}}=37.2 \mathrm{~kJ} \mathrm{~mol}^{-1}$ where significant contributions to the reaction come from both channels $10 \mathrm{a}$ and $10 \mathrm{~d}$ (the channel $10 \mathrm{c}$ is negligible). At $\mathrm{E}_{\mathrm{c}}=37.2 \mathrm{~kJ} \mathrm{~mol}^{-1} \sigma\left(\mathrm{CH}_{2} \mathrm{NH}+\mathrm{H}\right) / \sigma\left(\mathrm{CH}_{3} \mathrm{~N}+\mathrm{H}\right)$ is 0.25 . A large yield of $\mathrm{CH}_{3} \mathrm{~N}$ is not surprising at such a relatively large $\mathrm{E}_{\mathrm{c}}$ and corresponds to a well-known dynamical effect: the energy which is released after the insertion of $\mathrm{N}\left({ }^{2} \mathrm{D}\right)$ into the $\mathrm{C}-\mathrm{H}$ bond (corresponding to the exoergicity of $427 \mathrm{~kJ} \mathrm{~mol}^{-1}$ plus $\mathrm{E}_{\mathrm{c}}$ ) is initially 'localized' into the two new N-H and C-N bonds of the $\mathrm{CH}_{3} \mathrm{NH}$ intermediate. If one of the two newly formed (and very stressed) bonds breaks apart, we have the formation of either $\mathrm{NH}+\mathrm{CH}_{3}$ (corresponding to the fission of the new $\mathrm{C}-\mathrm{N}$ bond) or $\mathrm{CH}_{3} \mathrm{~N}+\mathrm{H}$ (corresponding to the fission of the new N-H bond). The fission of one of the pre-existing C-H bonds, not directly involved in the insertion process, can only occur if some energy redistribution takes place. For this to happen, the $\mathrm{CH}_{3} \mathrm{NH}$ should live long enough to allow for energy rearrangement. The trend of relative branching ratio with $\mathrm{E}_{\mathrm{c}}$ (it varies from 1.3 at $\mathrm{E}_{\mathrm{c}} \sim 20 \mathrm{~kJ} \mathrm{~mol}^{-1}$ to 0.03 at $\sim 60 \mathrm{~kJ} \mathrm{~mol}^{-1}$ [119]), confirms the above explanation: the larger is the total energy available to the system, the shorter is the intermediate lifetime and smaller the chance that the energy redistribution takes place efficiently. Notably, the trend with $\mathrm{E}_{\mathrm{c}}$ for the two channels (10a) and (10b) is expected to be similar, because in both cases the fission of one of the newly formed bonds is involved. Several implications for the atmospheric chemistry of Titan follow. The assumption that only $\mathrm{NH}$ and $\mathrm{CH}_{3}$ are the products of reaction (10) is wrong since that reactive channel is minor in the laboratory experiments and, by analyzing the trend of the branching ratio as a function of the available energy, we can presume that it will be even minor under the low temperature conditions of Titan's atmosphere. Therefore, the nitrogen chemistry that relies on the dominance of the $(10 \mathrm{~b})$ channel in the photochemical models of the atmosphere of Titan should be reconsidered. Furthermore, our results suggest that the reaction (10) is an active route of formation of methanimine, $\mathrm{CH}_{2} \mathrm{NH}$, a closed-shell molecule. $\mathrm{CH}_{2} \mathrm{NH}$ has been recently identified in the upper atmosphere of Titan [46] and in bulk experiments that mimic the atmosphere of Titan [181]. Interestingly, $\mathrm{CH}_{2} \mathrm{NH}$ contains a novel $\mathrm{C}-\mathrm{N}$ bond, thus demonstrating that such a bond can be generated directly by a reaction involving an active form of $\mathrm{N}_{2}$, the main constituent of the atmosphere of Titan, and $\mathrm{CH}_{4}$, the second most abundant species. The presence of an unsaturated $\mathrm{CN}$ bond renders $\mathrm{CH}_{2} \mathrm{NH}$ a reactive molecule and in a reducing environment like the atmosphere of Titan, methanimine could be converted to the fully saturated analogue methylamine. 
Alternatively, it could photodissociate to $\mathrm{HCN} / \mathrm{HNC}$ in one or two steps. Some laboratory information is available on the $\mathrm{UV}$ absorption cross sections of $\mathrm{CH}_{2} \mathrm{NH}$ [182] and on the fragmentation of internally excited methanimine [183]. It is, therefore, possible that an important route of $\mathrm{HCN}$ formation in the atmosphere of Titan is:

$$
\begin{gathered}
\mathrm{N}\left({ }^{2} \mathrm{D}\right)+\mathrm{CH}_{4} \rightarrow \mathrm{CH}_{2} \mathrm{NH}+\mathrm{H} \\
\mathrm{CH}_{2} \mathrm{NH}+\mathrm{h} v(\mathrm{UV}) \rightarrow \mathrm{HCN}+\mathrm{H}_{2}(\text { or } 2 \mathrm{H})
\end{gathered}
$$

Figure 5. Top, left: Laboratory angular distribution of the $\mathrm{CH}_{3} \mathrm{~N} / \mathrm{CH}_{2} \mathrm{NH}$ products from the reaction $\mathrm{N}\left({ }^{2} \mathrm{D}\right)+\mathrm{CH}_{4}$ at $\mathrm{E}_{\mathrm{c}}=37.2 \mathrm{~kJ} \mathrm{~mol}^{-1}$. The separate contributions to the total $\mathrm{LAB}$ angular distribution (solid line) from the $\mathrm{CH}_{3} \mathrm{~N}$ channel (dashed line) and the $\mathrm{CH}_{2} \mathrm{NH}$ channel (dotted line) are shown; top, right: best-fit CM product translational energy distributions for the methylnitrene (dashed line) and the methanimine (dotted line) forming channels. The arrows indicate the total available energy for the various isomer channels. Bottom: schematic potential energy surface for the $\mathrm{CH}_{4} \mathrm{~N}$ system. Reprinted with permission from reference [180].
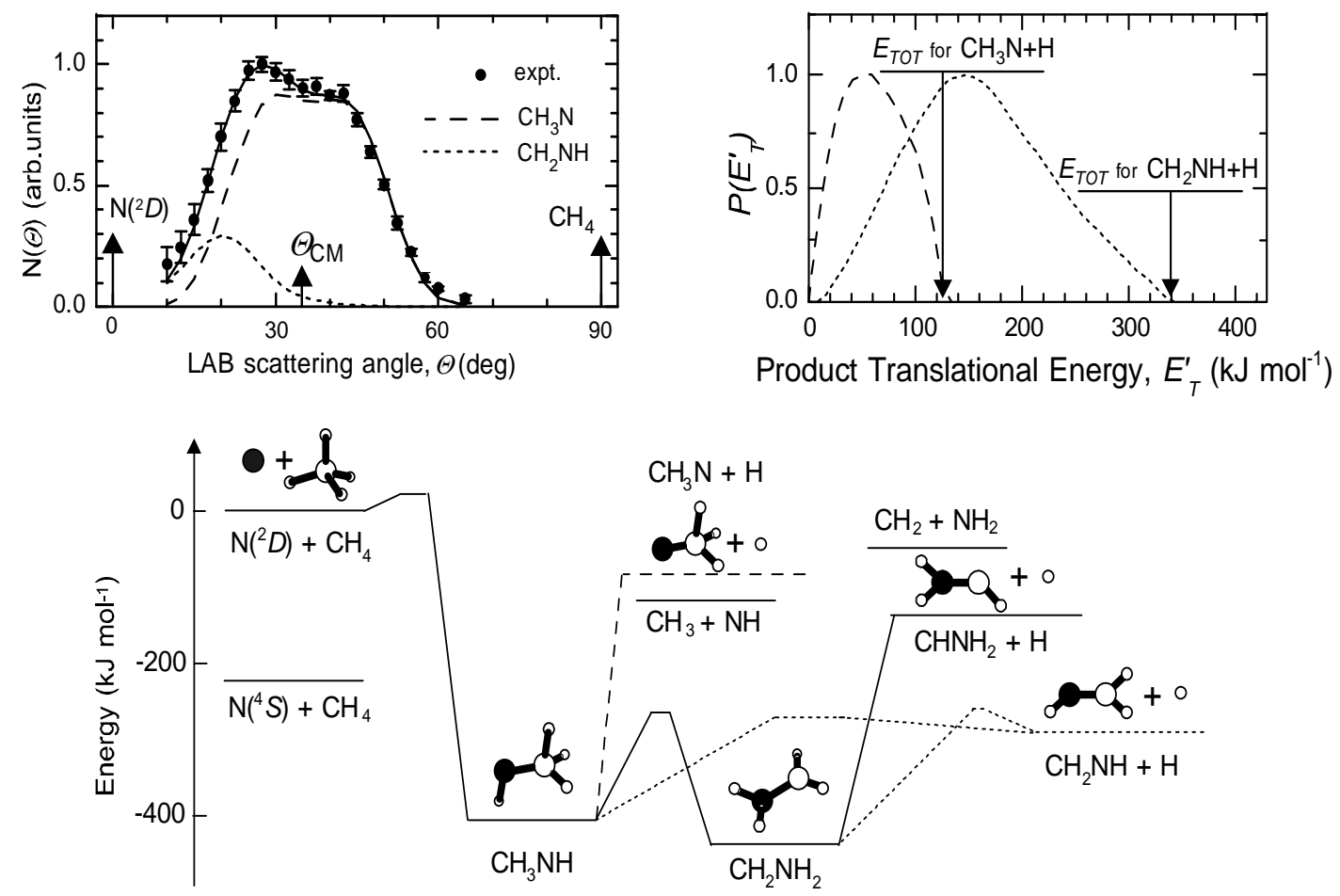

The reaction $\mathrm{N}\left({ }^{2} \mathrm{D}\right)+\mathrm{C}_{2} \mathrm{H}_{2}$ (11) was also investigated in $\mathrm{CMB}$ experiments with $\mathrm{MS}$ detection and the experimental results were consistent with both $\mathrm{HCCN}+\mathrm{H}$ and cyclic-HC(N)C $+\mathrm{H}$ formation [115] and essentially confirm the potential role of the $\mathrm{N}\left({ }^{2} \mathrm{D}\right)+\mathrm{C}_{2} \mathrm{H}_{2}$ reaction as the first step in the formation of $\mathrm{C}_{2} \mathrm{~N}_{2}$ and $\mathrm{C}_{2} \mathrm{~N}_{4}$. Probably the case which better represents the potentiality of our experimental technique is the reaction $\mathrm{N}\left({ }^{2} \mathrm{D}\right)+\mathrm{C}_{2} \mathrm{H}_{4}$ (13) [116]. This reaction was not considered in the early models, even though ethylene is almost as abundant as acetylene, or was considered erroneously [43]. The CMB-MS results clearly indicate that also this reaction proceeds through the formation of an addition intermediate and that products of general formula $\mathrm{C}_{2} \mathrm{H}_{3} \mathrm{~N}$ are formed through 
a N/H exchange channel [116]. The experimental findings gained support from the PES calculations by Takayanagi et al. [184] and are consistent with the formation of ketenimine and $2 \mathrm{H}$-azirine. It is very interesting to note, however, that according to the energy release - a piece of information which can be obtained only from a reaction dynamics experiment - a large fraction of the $2 \mathrm{H}$-azirine and ketenimine molecules are formed with enough internal energy to spontaneously tautomerize to the most stable isomer acetonitrile [116], even in a collision free environment. Therefore, reaction (13) can be considered an effective route which ultimately leads to the formation of $\mathrm{CH}_{3} \mathrm{CN}$. Our suggestion has been accepted and included in the models recently developed by Wilson and Atreya [45] and Lavvas et al. [48].

Very recent experimental results have become available on the reaction of $\mathrm{N}\left({ }^{2} \mathrm{D}\right)$ with another abundant hydrocarbon in the atmosphere of Titan, that is, $\mathrm{C}_{2} \mathrm{H}_{6}$. According to the preliminary analysis of the experimental distributions, $\mathrm{C}_{2} \mathrm{H}_{5} \mathrm{~N}$ isomers have been identified as a result of an $\mathrm{H}$-displacement channel [185].

Quite interestingly, all the reactions between $\mathrm{N}\left({ }^{2} \mathrm{D}\right)$ and hydrocarbons investigated so far are characterized by the formation of active radicals (such as $\mathrm{CH}_{3} \mathrm{~N}, \mathrm{HCCN}$ or $\mathrm{C}_{2} \mathrm{H}_{5} \mathrm{~N}$ ), cyclic nitriles (such as $2 \mathrm{H}$-azirine) and unsaturated nitriles (such as ketenimine, methanimine and ethanimine) (see Figure 6). These species can obviously react further with the other components of the relatively dense atmosphere of Titan. In particular, $\mathrm{CH}_{2} \mathrm{NH}$ can polymerize (in a similar manner as $\mathrm{H}_{2} \mathrm{CO}$ does) or copolymerize with the other unsaturated nitriles to form the Titan aerosol, which has been recently analyzed by the Aerosol Collector and Pyrolyser during the Huygens probe descent and found to be quite rich in nitrogen [186].

Figure 6. Nitriles and nitrile radicals observed as molecular products in the reactions of $\mathrm{N}\left({ }^{2} \mathrm{D}\right)$ with $\mathrm{CH}_{4}, \mathrm{C}_{2} \mathrm{H}_{2}$ and $\mathrm{C}_{2} \mathrm{H}_{4}$.

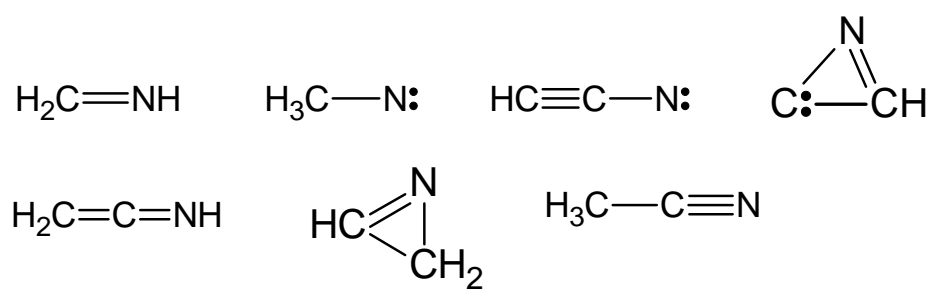

\section{Key Results On the Reactions of Atomic Sulfur, $S\left({ }^{1} D\right)$}

Simple organosulfur (C-S containing) compounds have been observed in ISCs, cometary comae and also in planetary atmospheres, raising the question of how they are formed under such different conditions [187-194]. Amongst those observations, probably the most striking one is the detection of $\mathrm{CS}, \mathrm{CS}_{2}$ and $\mathrm{S}_{2}$ after the impact of the comet Shoemaker-Levy 9 on Jupiter, where those species were observed after the impact for several days [190]. Some possible mechanisms of C-S bond formation were suggested [191] and several investigated in crossed beam experiments [192,193] and electronic structure calculations [194].

A substantial lack of experimental data, both at the level of kinetic investigation and of reaction dynamics, has so far prevented the role of the reactions of atomic sulfur with hydrocarbons or 
hydrocarbon radicals from being established in all of the above mentioned environments. In the light of the general interest of sulfur atom reactions and the paucity of experimental information on their reaction kinetics and especially dynamics, a systematic investigation of sulfur atom reaction kinetics and dynamics by means of the CRESU and CMB-MS techniques has been recently started $[132,133]$. The first results have just appeared in the literature [132,133] and revealed interesting information concerning the chemical behaviour of the sulfur atoms in the electronically excited state, ${ }^{1} \mathrm{D}$. S $\left({ }^{1} \mathrm{D}\right)$ can be produced in planetary atmospheres or cometary comae by the UV photodissociation of several precursor molecules, such as OCS [198] and $\mathrm{CS}_{2}$ [199] and even the photodissociation of $\mathrm{H}_{2} \mathrm{~S}$ at the Lyman- $\alpha$ wavelength can occur via a three body dissociation with $S\left({ }^{1} D\right)$ formation [200]. Also the UV photodissociation of radicals, such as $\mathrm{SH}$, leads to the formation of atomic sulfur in the first electronically excited state [201]. Since the lifetime of the metastable excited state is long enough (28 s), sulfur atoms in the excited ${ }^{1} \mathrm{D}$ state may well react with other gaseous species provided that the density is not too low. To be noted that the UV photodissociation of $\mathrm{H}_{2} \mathrm{~S}$ in the primeval terrestrial atmosphere has been suggested as a possible initiating step of gas-phase prebiotic synthesis [7].

The reaction mechanisms inferred for the two reactions $\mathrm{S}\left({ }^{1} \mathrm{D}\right)+\mathrm{C}_{2} \mathrm{H}_{2}$ and $\mathrm{S}\left({ }^{1} \mathrm{D}\right)+\mathrm{C}_{2} \mathrm{H}_{4}$ share similar features [132,133]: the electrophilic $\mathrm{S}\left({ }^{1} \mathrm{D}\right)$ atom adds, without any barrier, to the multiple bond of acetylene or ethylene, forming an internally excited cyclic intermediate (thiirene and thiirane in the two cases). Once formed, thiirene can directly rearrange to $\mathrm{H}_{2} \mathrm{CCS}$ (thioketene, the most stable isomer along the singlet $\mathrm{C}_{2} \mathrm{H}_{2} \mathrm{~S}$ PES), which, in turn, dissociates into HCCS $+\mathrm{H}$. In an alternative pathway, the PES minimum configuration of thioketene is never reached and the succession of rearrangements after thiirene formation is isomerization to $\mathrm{CC}(\mathrm{H}) \mathrm{SH}$ followed by isomerization to HCCSH which, in turn, can undergo an S-H bond fission to HCCS $+\mathrm{H}$. In both pathways, HCCS $+\mathrm{H}$ are the only possible products. Thiirane, the cyclic intermediate formed by the reaction of $S\left({ }^{1} \mathrm{D}\right)$ with ethylene, can directly undergo ring-opening and three-center $\mathrm{H}_{2}$ elimination to thioketene $\left(\mathrm{CH}_{2} \mathrm{CS}\right)+\mathrm{H}_{2}$ (the least abundant channel, with a yield of $7 \%$ ) or, more readily, isomerize to vinylthiol $\left(\mathrm{CH}_{2} \mathrm{CHSH}\right)$ which can undergo $\mathrm{C}-\mathrm{H}$ bond rupture to thiovinoxy $\left(\mathrm{CH}_{2} \mathrm{CHS}\right)+\mathrm{H}$ (the second channel in importance, with a yield of 0.15$)$. Vinylthiol can also isomerize to the slightly more stable thio-acetaldehyde $\left(\mathrm{CH}_{3} \mathrm{CHS}\right)$, which can undergo $\mathrm{C}-\mathrm{C}$ bond cleavage to $\mathrm{CH}_{3}+\mathrm{HCS}$ (the main reaction channel, with a yield of $78 \%$ ). The reaction $\mathrm{S}\left({ }^{1} \mathrm{D}\right)+\mathrm{C}_{2} \mathrm{H}_{4}$ was also investigated by the CRESU technique and was found to remain rapid down to the very low temperature of $23 \mathrm{~K}$, occurring without any activation energy. This is corroborated by the theoretical calculations of the singlet $\mathrm{C}_{2} \mathrm{H}_{4} \mathrm{~S}$ PES which did not find any appreciable reaction barrier to addition of $S\left({ }^{1} D\right)$ to the ethene molecule forming an initial thiirane stable intermediate. These first results on $\mathrm{S}\left({ }^{1} \mathrm{D}\right)$ reactions with hydrocarbons have shown that simple organo-sulfur compounds can be formed in relatively dense gaseous environments, provided that simple precursor molecules of sulfur atoms and UV light are available in the presence of simple hydrocarbons. These experimental findings might have several implications for the formation of prebiotic important organosulfur compounds. 


\section{Conclusions}

In this paper, two powerful experimental techniques devoted to the study of bimolecular, neutralneutral reactions have been described and their contributions to the understanding of several gas-phase reactions leading to prebiotic molecules illustrated.

It should be stressed that these experimental approaches are such that they can only focus on one elementary reaction at a time, while the complex reaction networks that describe the chemistry of interstellar clouds and planetary atmospheres comprise hundreds or thousands elementary reactions. It is, therefore, important that a collaboration is established with modelers and astronomers, so that the possibly relevant reactions and molecular species are recognized and the experimental effort is directed towards them. In this respect, positive initiatives have been two multidisciplinary EU networks, Molecular Universe and Europlanet, where physical chemists and astronomers/planetologists have had the chance to communicate and exchange ideas. Also, sensitivity methods applied to the models of ISCs and planetary atmospheres are of great help in identifying the critical reactions that should be better characterized in the laboratory to improve the reliability of the models [202-205].

\section{Acknowledgements}

I wish to thank Andre Canosa for providing the figures on the CRESU experimental set-up and results. Special thanks go to my previous and current collaborators, in particular Ralf Kaiser and Piero Casavecchia. I am grateful to Dimitris Skouteris for comments on the manuscript. Finally, I wish to thank C. Ceccarelli, S. Viti, A. Lazcano, J.R. Brucato, E. Gallori, E. De Mauro, J.I. Lunine and Y. Keheyan for stimulating discussions on astrochemistry and prebiotic chemistry.

I acknowledge financial support from the Italian MIUR (Ministero Istruzione Università Ricerca) under projects PRIN (2007H9S8SW_004) and European Commission through the Coordination Action 001637 (Europlanet). This work is also supported by the European Union Marie-Curie human resources and mobility programme under contract MCRTN-CT-2004-512302 (Molecular Universe).

\section{References and Notes}

1. Eschenmoser, A.; Loewenthal, E. Chemistry of potentially prebiological natural products. Chem. Soc. Rev. 1992, 21, 1-16.

2. Eschenmoser, A. Chemistry of potentially prebiological natural products. Orig. Life Evol. Biosph. 1994, 24, 389-423.

3. Bernstein, M. Prebiotic materials from on and off the early Earth. Phil. Trans. R. Soc. B 2006, 361, 1689-1702.

4. Chyba, C.; Sagan, C. Endogenous production, exogenous delivery and impact-shock synthesis of organic molecules: an inventory for the origins of life. Nature 1992, 355, 125-132.

5. Miller, S.L. Production of amino acids under possible primitive Earth conditions. Science 1953, $117,528-529$. 
6. Bada, J.J.; Lazcano, A. Prebiotic soup - revisiting the miller experiment. Science 2003, 300, 745-746.

7. Miller, S.L. Current status of the prebiotic synthesis of small molecules. Chem. Scripta 1986, 26B, 5-11.

8. Cleaves, H.J.; Chalmers, J.H.; Lazcano, A.; Miller, S.L.; Bada J.L. A reassessment of prebiotic organic synthesis in neutral planetary atmospheres. Orig. Life Evol. Biosph. 2008, 38, 105-115.

9. Johnson, A.P.; Cleaves, H.J.; Dworkin, J.P.; Glavin, D.P.; Lazcano, A.; Bada, J.L. The Miller volcanic spark discharge experiment. Science 2008, 322, 404-404.

10. Holm, N.G.; Andersson, E. Hydrothermal simulation experiments as a tool for studies of the origin of life on earth and other terrestrial planets: a review. Astrobiology 2005, 5, 444-460; And references therein.

11. Ehrenfreund, P.; Irvine, W.; Becker, L.; Blank, J.; Brucato, J.R.; Colangeli, L.; Derenne, S.; Despois, D.; Dutrey, A.; Fraaije, H.; Lazcano, A.; Owen, T.; Robert, F. Astrophysical and astrochemical insights into the origin of life. Rep. Prog. Phys. 2002, 65, 1427-1487.

12. Ehrenfreund, P.; Charnley, S.B. Organic molecules in the interstellar medium, comets, and meteorites: A voyage from dark clouds to the early earth. Ann. Rev. Astron. Astrophys. 2000, 38, 427-483.

13. Orò, J.; Mills, T.; Lazcano, A. Comets and the formation of biochemical compounds on the primitive Earth - a review. Orig. Life Evol. Biosph. 1991, 21, 267-277.8.

14. Pizzarello, S. The chemistry of life's origin: a carbonaceous meteorite perspective. Acc. Chem. Res. 2006, 39, 231-237.

15. Martins, Z.; Botta, O.; Fogel, M.L.; Sephton, M.A.; Glavin, D.P.; Watson, J.S.; Dworkin, J.P.; Schwartz, A.W.; Ehrenfreund, P. Extraterrestrial nucleobases in the Murchison meteorite. Earth Planet. Sci. Lett. 2008, 270, 130-136.

16. Flynn, G.J.; Keller, L.P.; Jacobsen, C.; Wirick, S. An assessment of the amount and types of organic matter contributed to the Earth by interplanetary dust. Adv. Space Res. 2004, 33, 57-66.

17. A continuously updated list of the observed molecules is available online: http://ww.astrochymist.org.

18. Ehrenfreund, P.; Bernstein, M.P.; Dworkin, J.P.; Sandford, S.A.; Allamandola, L.J. The photostability of amino acids in space. Astrophys. J. 2001, 550, L95-L99.

19. See, for instance, Stantcheva, T.; Herbst, E. Models of gas-grain chemistry in interstellar cloud cores with a stochastic approach to surface chemistry. Astron. Astrophys. 2004, 423, 241-251.

20. Roberge, W.G.; Jones, D.; Lepp, S.; Dalgarno A. Interstellar photodissociation and photoionization rates. Astrophys. J. Suppl. Ser. 1991, 77, 287-297.

21. Tielens, A.G.G.M. The physics and chemistry of the interstellar medium; Cambridge University Press: Cambridge, UK, 2005.

22. Herbst, E.; Millar, T.I. The chemistry of cold interstellar cloud cores. In Low Temperatures and cold molecules; Smith, I.W.M., Ed.; Imperial College Press, World Scientific Publishing Co. Pte. Ltd.: Singapore, 2008; pp. 1-54.

23. Mitchell, G.F. Effects of shocks on the molecular composition of a dense interstellar cloud. Astrophys. J. Suppl. Ser. 1984, 54, 81-101.

24. Herbst, E. Chemistry of Star-Forming Regions. J. Phys. Chem. A 2005, 109, 4017-4029. 
25. Le Teu, Y.H.; Millar, T.J.; Markwick, A.J. The UMIST database for astrochemistry 1999. Astron. Astrophys. Suppl. Ser. 2000, 146, 157-168.

26. Turner, B.E.; Herbst, E.; Terzieva, R. The physics and chemistry of small translucent molecular clouds. XIII. The basic hydrocarbon chemistry. Astrophys. J. Suppl. Ser. 2000, 26, 427-460.

27. Yung, Y.L.; DeMore, W.B. Photochemistry of Planetary Atmospheres; Oxford University Press: New York, USA, 1998.

28. Mitchell, G.F.; Prasad, S.S.; Huntress, W.T. Chemical model calculations of $\mathrm{C}_{2}, \mathrm{C}_{3}, \mathrm{CH}, \mathrm{CN}$, $\mathrm{OH}$, and $\mathrm{NH}_{2}$ abundances in cometary comae. Astrophys. J. 1981, 244, 1087-1093.

29. Anicich, V.G. A survey of bimolecular ion-molecule reactions for use in modeling the chemistry of planetary-atmospheres, cometary comae, and interstellar clouds. Astrophys. J. Suppl. Ser. 1993, 84, 215-315.

30. Cottin, H.; Gazeau, M.C.; Raulin, F. Cometary organic chemistry: a review from observations, numerical and experimental simulations. Planet. Space Sci. 1999, 47, 1141-1162.

31. Kaiser, R.I. Experimental investigation on the formation of carbon-bearing molecules in the interstellar medium via neutral-neutral reactions. Chem. Rev. 2002, 102, 1309-1358.

32. Smith, D. The ion chemistry of interstellar clouds. Chem. Rev. 1992, 92, 1473-1485.

33. Canosa, A.; Goulay, F.; Sims, I.R.; Rowe, B.R. Gas phase reactive collisions at very low temperature: recent experimental advances and perspectives. In Low Temperatures and cold molecules; Smith, I.W.M., Ed.; Imperial College Press, World Scientific Publishing Co. Pte. Ltd.: Singapore, 2008; pp. 55-120.

34. Smith, I.W.M.; Herbst, E.; Chang, Q. Rapid neutral-neutral reactions at low temperatures: a new network and first results for TMC-1. Mon. Not. R. Astronom. Soc. 2004, 350, 323-330.

35. Smith, I.W.M. The temperature-dependence of elementary reaction rates: beyond Arrhenius. Chem. Soc. Rev. 2008, 37, 812-826.

36. Strobel, D.F. Photochemistry in outer Solar System atmospheres. Space Sci. Rev. 2005, 116, 155-170.

37. Moses, J.I.; Bezard, B.; Lellouch, E.; Gladstone, G.R.; Feuchtgruber, H.; Allen, M. Photochemistry of Saturn's atmosphere. I. Hydrocarbon chemistry and comparisons with ISO observations. Icarus 2000, 143, 244-298.

38. Atreya, S.K. Uranus photochemistry and prospects for Voyager 2 at Neptune. Adv. Space Res. 1990, 10, 113-119.

39. Bishop, J.; Romani, P.N.; Atreya, S. Voyager 2 ultraviolet spectrometer solar occultations at Neptune: photochemical modeling of the 125-165 nm light curves. Planet. Space Sci. 1998, 46, $1-20$.

40. Romani, P.N.; Bishop, J.; Bezard, B.; Atreya, S. Methane photochemistry on Neptune: ethane and acetilene mixing ratios and haze production. Icarus 1993, 106, 442-463.

41. Yung, Y.; Allen, M.; Pinto, J. Photochemistry of the atmosphere of Titan - comparison between model and observations. Astrophys. J. Suppl. Ser. 1984, 55, 465-506.

42. Toublanc, D.; Parisot, J.; Brillet, J.; Gautier, D.; Raulin, F.; McKay, C. Photochemical modeling of Titan's atmosphere. Icarus 1995, 113, 2-26.

43. Lara, L.M.; Lellouch, E.; López-Moreno, J.J.; Rodrigo, R. Vertical distribution of Titan's atmospheric neutral constituents. J. Geophys. Res. 1996, 101, 23261-23283. 
44. Lebonnois, S.; Toublanc, D.; Hourdin, F.; Rannou, P. Seasonal variations of Titan's atmospheric composition. Icarus 2001, 152, 384-406.

45. Wilson, E.H.; Atreya, S. Current state of modeling the photochemistry of Titan's mutually dependent atmosphere and ionosphere. J. Geophys. Res. 2004, 109, E06002.

46. Vuitton, V.; Yelle, R.V.; Anicich, V.G. The nitrogen chemistry of Titan's upper atmosphere revealed. Astrophys. J. 2006, 647, L175-L178.

47. Lavvas, P.P.; Coustenis, A.; Vardavas, I.M. Coupling photochemistry with haze formation in Titan's atmosphere, part I: Model description. Planet. Space Sci. 2008, 56, 27-66.

48. Lavvas, P.P.; Coustenis, A.; Vardavas, I.M. Coupling photochemistry with haze formation in Titan's atmosphere. Part II: results and validation with Cassini/Huygens data. Planet. Space Sci. 2008, 56, 67-99.

49. Sagan, C., Thompson, W.R., Khare, B.N. Titan: a laboratory for prebiological organic chemistry Acc. Chem. Res. 1992, 25, 286-292.

50. Coustenis, A.; Taylor, F.W. Titan: the Earth-like Moon; World Scientific: Singapore, 1999.

51. Owen, T.; Raulin, F.; McKay, C.P.; Lunine, J.I.; Lebreton, J.P.; Matson, D.L. The Relevance of Titan and Cassini/Huygens to Pre-Biotic Chemistry and the Origin of Life on Earth. In Huygens: Science, Payload and Mission; Lebreton, J.P., Wilson, A., Eds.; ESA-ESTEC: Noordwijk, the Netherlands, August, 1997; pp. 231-233, ESA SP-1177.

52. Raulin, F. Astrobiology and habitability of Titan. Space Sci. Rev. 2008, 135, 37-8.

53. Roy, D.; Najafian, K.; Schleyer, P.v.R. Chemical evolution: the mechanism of the formation of adenine under prebiotic conditions. Proc. Natl. Acad. Sci. U.S.A. 2007, 104, 17272-17277.

54. Glaser, R.; Hodgen, B.; Farrelly, D.; McKee, E. Adenine synthesis in interstnellar space: mechanisms of prebiotic pyrimidine-ring formation of monocyclic HCN-pentamers. Astrobiology 2007, 7, 455-470.

55. Woon, D.E. Pathways to glycine and other amino acids in ultraviolet-irradiated astrophysical ices determined via quantum chemical modeling. Astrophys. J. 2002, 571, L177-L180.

56. Lee, Y.T. Molecular beam studies of elementary chemical processes. In Nobel Lectures in Chemistry 1981-1990; Fraegsmyr, T., Malstrom, B.G., Eds.; World Scientific: Singapore, 1992; pp. 320-357.

57. Smith, I.W.M.; Rowe, B.R. Reaction kinetics at very low temperatures: laboratory studies and interstellar chemistry. Acc. Chem. Res. 2000, 33, 261-268.

58. Smith, I.W.M. The Liversidge Lecture $2001-02$. Chemistry amongst the stars: reaction kinetics at a new frontier. Chem. Soc. Rev. 2002, 31, 137-146.

59. Smith, I.W.M. Laboratory studies of atmospheric reactions at low temperature. Chem. Rev. 2003, 103, 4549-4564.

60. Chastaing, D.; Le Picard, S.D.; Sims, I.R.; Smith I.W.M. Rate coefficients for the reactions of $\mathrm{C}\left({ }^{3} \mathrm{P}_{\mathrm{J}}\right)$ atoms with $\mathrm{C}_{2} \mathrm{H}_{2}, \mathrm{C}_{2} \mathrm{H}_{4}, \mathrm{CH}_{3} \equiv \mathrm{CCH}$ and $\mathrm{H}_{2} \mathrm{CCCH}_{2}$ at temperatures down $15 \mathrm{~K}$. Astron. Astrophys. 2001, 365, 241-247.

61. Chastaing, D.; Le Picard, S.D.; Sims, I.R.; Smith I.W.M.; Geppert, W.D.; Naulin, C.; Costes, M. Rate coefficients and cross-sections for the reactions of $\mathrm{C}\left({ }^{3} \mathrm{P}_{\mathrm{J}}\right)$ atoms with methylacetylene and allene. Chem. Phys. Lett. 2000, 331, 170-176. 
62. Canosa, A.; Le Picard, S.D.; Gougeon, S.; Rebrion-Rowe, C.; Travers, D.; Rowe, B.R. Rate coefficients for the reactions of $\left.\mathrm{Si}^{3}{ }^{3} \mathrm{P}_{\mathrm{J}}\right)$ with $\mathrm{C}_{2} \mathrm{H}_{2}$ and $\mathrm{C}_{2} \mathrm{H}_{4}$ : Experimental results down to $15 \mathrm{~K}$. J. Chem. Phys. 2001, 115, 6495-6503.

63. Sims, I.R.; Queffelec, J.L.; Defrance, A.; Rebrion-Rowe, C.; Travers, D.; Bocherel, P.; Rowe, B.R.; Smith I.W.M. Ultralow temperature kinetics of neutral-neutral reactions - the technique and results for the reactions $\mathrm{CN}+\mathrm{O}_{2}$ down to $13 \mathrm{~K}$ and $\mathrm{CN}+\mathrm{NH}_{3}$ down to $25 \mathrm{~K}$. J. Chem. Phys. 1994, 100, 4229-4241.

64. Goulay, F.; Rebrion-Rowe, C.; Biennier, L.; Le Picard, S.D.; Canosa, A.; Rowe, B.R. The reaction of anthracene with $\mathrm{CH}$ radicals: An experimental study of the kinetics between $58 \mathrm{~K}$ and 470 K. J. Phys. Chem. A. 2006, 110, 3132-3137.

65. Goulay, F.; Rebrion-Rowe, C.; Le Garrec, J.L.; Le Picard, S.D.; Canosa, A.; Rowe, B.R. The reaction of anthracene with $\mathrm{OH}$ radicals: an experimental study of the kinetics between $58 \mathrm{~K}$ and 470 K. J. Chem. Phys. 2005, 122, 104308. 66.

66. Brownsword, R.A.; Canosa, A.; Rowe, B.R.; Sims, I.R.; Smith, I.W.M.; Stewart, D.W.A.; Symonds, A.C.; Travers, D. Kinetics over a wide range of temperature $(13-744 \mathrm{~K})$ : rate constants for the reactions $\mathrm{CH}(\mathrm{v}=0)$ with $\mathrm{H}_{2}$ and $\mathrm{D}_{2}$ and for the removal of $\mathrm{CH}(\mathrm{v}=1)$ by $\mathrm{H}_{2}$ and $\mathrm{D}_{2}$ J. Chem. Phys. 1997, 106, 7662-7677.

67. Sims, I.R.; Queffelec, J.L.; Travers, D.; Rowe, B.R.; Herbert, L.B.; Karthauser, J., Smith, I.W.M. Rate constants for the reactions of $\mathrm{CN}$ with hydrocarbons at low and ultra-low temperature. Chem. Phys. Lett. 1993, 211, 461-468.

68. Canosa, A.; Sims, I.R.; Travers, D.; Smith, I.W.M.; Rowe, B.R. Reactions of the methylidine radical with $\mathrm{CH}_{4}, \mathrm{C}_{2} \mathrm{H}_{2}, \mathrm{C}_{2} \mathrm{H}_{4}, \mathrm{C}_{2} \mathrm{H}_{6}$ and but-1-ene studied between 23 and $295 \mathrm{~K}$ with a CRESU apparatus. Astron. Astrophys. 1997, 323, 644-651.

69. Chastaing, D.; James, P.L.; Sims, I.R.; Smith, I.W.M. Neutral-neutral reactions at the temperatures of interstellar clouds - Rate coefficients for reactions of $\mathrm{C}_{2} \mathrm{H}$ radicals with $\mathrm{O}_{2}, \mathrm{C}_{2} \mathrm{H}_{2}$, $\mathrm{C}_{2} \mathrm{H}_{4}$ and $\mathrm{C}_{3} \mathrm{H}_{6}$ down to $15 \mathrm{~K}$. Faraday Discuss. 1998, 109, 165-181.

70. Berteloite, C.; Le Picard, S.D.; Birza, P.; Gazeau, M.C.; Canosa, A.; Benilan, Y.; Sims, I.R. Low temperature $(39 \mathrm{~K}-298 \mathrm{~K})$ kinetic study of the reactions of $\mathrm{C}_{4} \mathrm{H}$ radical with various hydrocarbons observed in Titan's atmosphere: $\mathrm{CH}_{4}, \mathrm{C}_{2} \mathrm{H}_{2}, \mathrm{C}_{2} \mathrm{H}_{4}, \mathrm{C}_{2} \mathrm{H}_{6}, \mathrm{C}_{3} \mathrm{H}_{4}$ and $\mathrm{C}_{3} \mathrm{H}_{8}$. Icarus 2008, 194, 746-757.

71. Canosa, A.; Paramo, A.; Le Picard, S.D.; Sims, I.R. An experimental study of the reaction kinetics of $\mathrm{C}_{2}\left(\mathrm{X}^{1} \Sigma_{\mathrm{g}}^{+}\right)$with hydrocarbons $\left(\mathrm{CH}_{4}, \mathrm{C}_{2} \mathrm{H}_{2}, \mathrm{C}_{2} \mathrm{H}_{4}, \mathrm{C}_{2} \mathrm{H}_{6}\right.$ and $\left.\mathrm{C}_{3} \mathrm{H}_{8}\right)$ over the temperature range $24-300 \mathrm{~K}$. Implications for the atmospheres of Titan and the Giant Planets. Icarus 2007, 187, 558-568.

72. Paramo, A.; Canosa, A.; Le Picard, S.D.; Sims, I.R. Rate coefficients for the reactions of $\mathrm{C}_{2}\left(\mathrm{a}^{3} \Pi_{\mathrm{u}}\right)$ and $\mathrm{C}_{2}\left(\mathrm{X}^{1} \Sigma^{+} \mathrm{g}\right)$ with various hydrocarbons $\left(\mathrm{CH}_{4}, \mathrm{C}_{2} \mathrm{H}_{2}, \mathrm{C}_{2} \mathrm{H}_{4}, \mathrm{C}_{2} \mathrm{H}_{6}\right.$, and $\left.\mathrm{C}_{3} \mathrm{H}_{8}\right)$ : A gasphase experimental study over the temperature range 24-300 K. J. Phys. Chem. A 2008, 112, 9591-9600.

73. Atkinson, D.B.; Smith, M.A. Design and characterization of pulsed uniform supersonic expansions for chemical applications. Rev. Sci. Instrum. 1995, 66, 4434-4446. 
74. Lee, S.; Hoobler, R.J.; Leone, S.R. A pulsed Laval nozzle apparatus with laser ionization mass spectrometry for direct measurements of rate coefficients at low temperatures with condensable gases. Rev. Sci. Instrum. 2000, 71, 1816-1823.

75. Spangenberg, T.; Kohler, S.; Hansmann, B.; Wachsmuth, U.; Abel, B.; Smith, M.A. Lowtemperature reactions of $\mathrm{OH}$ radicals with propene and isoprene in pulsed Laval nozzle expansions. J. Phys. Chem. A 2004, 108, 7527-7534.

76. Mullen, C.; Smith, M.A. Low temperature $\mathrm{NH}\left(\mathrm{X}^{3} \Sigma^{-}\right)$radical reactions with $\mathrm{NO}$, saturated, and unsaturated hydrocarbons studied in a pulsed supersonic Laval nozzle flow reactor between 53 and 188 K. J. Phys. Chem. A 2005, 109, 1391-1399.

77. Vakhtin, A.B.; Heard, D.E.; Smith, I.W.M.: Leone, S.R. Kinetics of $\mathrm{C}_{2} \mathrm{H}$ radical reactions with ethene, propene and 1-butene measured in a pulsed Laval nozzle apparatus at T-103 and $296 \mathrm{~K}$. Chem. Phys. Lett. 2001, 348, 21-26.

78. Goulay, F.; Leone, S.R. Low-temperature rate coefficients for the reaction of ethynyl radical $\left(\mathrm{C}_{2} \mathrm{H}\right)$ with benzene. J Phys. Chem. A 2006, 110, 1875-1880.

79. Nizamov, B.; Leone, S.R. Kinetics of $\mathrm{C}_{2} \mathrm{H}$ reactions with hydrocarbons and nitriles in the $104-$ 296 K temperature range. J Phys. Chem. A 2004, 108, 1746-1752.

80. Vakhtin, A.B.; Murphy, J.E.; Leone, S.R. Low-temperature kinetics of reactions of OH radical with ethene, propene, and 1-butene. J Phys. Chem. A 2003, 107, 10055-10062.

81. Murphy, J.E.; Vakhtin, A.B.; Leone, S.R. Laboratory kinetics of $\mathrm{C}_{2} \mathrm{H}$ radical reactions with ethane, propane, and n-butane at $\mathrm{T}=96-296 \mathrm{~K}$ : implications for Titan. Icarus 2003, 163, 175-181.

82. Vakhtin, A.B.; Heard, D.E.; Smith, I.W.M.; Leone, S.R. Kinetics of reactions of $\mathrm{C}_{2} \mathrm{H}$ radical with acetylene, $\mathrm{O}_{2}$, methylacetylene, and allene in a pulsed Laval nozzle apparatus at $\mathrm{T}=103 \mathrm{~K}$. Chem. Phys. Lett. 2001, 344, 317-324.

83. Hansmann, B.; Abel B. Kinetics in cold Laval nozzle expansions: From atmospheric chemistry to oxidation of biomolecules in the gas phase. Chem. Phys. Chem. 2007, 8, 343-356.

84. Balucani, N.; Asvany, O.; Huang, L.C.L.; Lee, Y.T.; Kaiser, R.I.; Osamura, Y.; Bettinger, H.F. Formation of nitriles in the interstellar medium via reactions of cyano radicals, $\mathrm{CN}\left(\mathrm{X}^{2} \Sigma^{+}\right)$, with unsaturated hydrocarbons. Astrophys. J. 2000, 545, 892-906.

85. Balucani, N.; Asvany, O.; Osamura, Y.; Huang, L.C.L.; Lee, Y.T.; Kaiser, R.I. Laboratory investigation on the formation of unsaturated nitriles in Titan's atmosphere. Planet. Space Sci. 2000, 48, 447-462.

86. Kaiser, R.I.; Balucani, N. Astrobiology - the final frontier in chemical reaction dynamics. Int. J. Astrobiology 2002, 1, 15-23.

87. Kaiser, R.I.; Balucani, N. The formation of nitriles in hydrocarbon-rich atmospheres of planets and their satellites: Laboratory investigations by the crossed molecular beam technique. Acc. Chem. Res. 2001, 34, 699-706.

88. Zhang, F.T.; Kim, S.; Kaiser, R.I.; Mebel, A.M. Formation of the 1,3,5-hexatriynyl radical $\left(\mathrm{C}_{6} \mathrm{H}\left(\mathrm{X}^{2} \Pi\right)\right)$ via the crossed beams reaction of dicarbon $\left(\mathrm{C}_{2}\left(\mathrm{X}^{1} \Sigma^{+}{ }_{\mathrm{g}} / \mathrm{a}^{3} \mathrm{II}_{\mathrm{u}}\right)\right)$, with diacetylene $\left(\mathrm{C}_{4} \mathrm{H}_{2}\left(\mathrm{X}^{1} \Sigma^{+} \mathrm{g}\right)\right)$. J Phys. Chem. A 2009, 113, 1210-1217.

89. Gu, X.B.; Guo, Y.; Mebel, A.M.; Kaiser, R.I. Chemical dynamics of the formation of the 1,3butadiynyl radical $\left(\mathrm{C}_{4} \mathrm{H}\left(\mathrm{X}^{2} \Sigma^{+}\right)\right)$and its isotopomers. J Phys. Chem. A 2006, 110, 11265-11278. 
90. Kaiser, R.I.; Balucani, N.; Charkin, D.O.; Mebel, A.M. A crossed beam and ab initio study of the $\mathrm{C}_{2}\left(\mathrm{X}^{1} \Sigma_{\mathrm{g}}^{+} / \mathrm{a}^{3} \Pi_{\mathrm{u}}\right)+\mathrm{C}_{2} \mathrm{H}_{2}\left(\mathrm{X}^{1} \Sigma_{\mathrm{g}}^{+}\right)$reactions. Chem. Phys. Lett. 2003, 382, 112-119.

91. Kaiser, R.I.; Le, T.N.; Nguyen, T.L.; Mebel, A.M.; Balucani, N.; Lee, Y.T.; Stahl, F.; Schleyer, P.V.; Schaefer, H.F. A combined crossed molecular beam and ab initio investigation of $\mathrm{C}_{2}$ and $\mathrm{C}_{3}$ elementary reactions with unsaturated hydrocarbons - pathways to hydrogen deficient hydrocarbon radicals in combustion flames. Faraday Discuss. 2001, 119, 51-66.

92. Balucani, N.; Mebel, A.M.; Lee, Y.T.; Kaiser, R.I. A combined crossed molecular beam and ab initio study of the reactions $\mathrm{C}_{2}\left(\mathrm{X}^{1} \Sigma_{\mathrm{g}}^{+} / \mathrm{a}^{3} \mathrm{II}_{\mathrm{u}}\right)+\mathrm{C}_{2} \mathrm{H}_{4} \rightarrow \mathrm{n}-\mathrm{C}_{4} \mathrm{H}_{3}\left(\mathrm{X}^{2} \mathrm{~A}^{\prime}\right)+\mathrm{H}\left({ }^{2} \mathrm{~S}_{1 / 2}\right)$. J Phys. Chem. A 2001, 105, 9813-9818.

93. Guo, Y.; Gu, X.; Balucani, N.; Kaiser, R.I. Formation of the 2,4-pentadiynyl-1 radical $\left(\mathrm{H}_{2} \mathrm{CCCCCH}, \mathrm{X}^{2} \mathrm{~B}_{1}\right)$ in the crossed beams reaction of dicarbon molecules with methylacetylene. J Phys. Chem. A 2006, 110, 6245-6249.

94. Gu, X.B.; Guo, Y.; Zhang, F.T.; Mebel, A.M.; Kaiser, R.I. Reaction dynamics of carbon-bearing radicals in circumstellar envelopes of carbon stars. Faraday Discuss. 2006, 133, 245-275.

95. Gu, X.B.; Zhang, F.T.; Kaiser, R.I. Reaction dynamics on the formation of 1-and 3cyanopropylene in the crossed beams reaction of ground-state cyano radicals $(\mathrm{CN})$ with propylene $\left(\mathrm{C}_{3} \mathrm{H}_{6}\right)$ and its deuterated isotopologues. J Phys. Chem. A 2008, 112, 9607-9612.

96. Balucani, N.; Asvany, O.; Kaiser, R.I.; Osamura, Y. Formation of three $\mathrm{C}_{4} \mathrm{H}_{3} \mathrm{~N}$ isomers from the reaction of $\mathrm{CN}\left(\mathrm{X}^{2} \Sigma^{+}\right)$with allene, $\mathrm{H}_{2} \mathrm{CCCH}_{2}\left(\mathrm{X}^{1} \mathrm{~A}_{1}\right)$, and methylacetylene, $\mathrm{CH}_{3} \mathrm{CCH}\left(\mathrm{X}^{1} \mathrm{~A}_{1}\right)$ : a combined crossed beam and ab initio study. J Phys. Chem. A 2002, 106, 4301-4311.

97. Balucani, N.; Asvany, O.; Chang, A.H.H.; Lin, S.H.; Lee, Y.T.; Kaiser, R.I.; Osamura, Y. Crossed beam reaction of cyano radicals with hydrocarbon molecules. III. Chemical dynamics of vinylcyanide $\left(\mathrm{C}_{2} \mathrm{H}_{3} \mathrm{CN} ; \mathrm{X}^{1} \mathrm{~A}^{\prime}\right)$ formation from reaction of $\mathrm{CN}\left(\mathrm{X}^{2} \Sigma^{+}\right)$with ethylene, $\mathrm{C}_{2} \mathrm{H}_{4}\left(\mathrm{X}^{1} \mathrm{~A}_{\mathrm{g}}\right)$. J. Chem. Phys. 2000, 113, 8643-8655.

98. Huang, L.C.L.; Asvany, O.; Chang, A.H.H.; Balucani, N.; Lin, S.H.; Lee, Y.T.; Kaiser, R.I.; Osamura, Y. Crossed beam reaction of cyano radicals with hydrocarbon molecules. IV. Chemical dynamics of cyanoacetylene $\left(\mathrm{HCCCN} ; \mathrm{X}^{1} \Sigma^{+}\right)$formation from reaction of $\mathrm{CN}\left(\mathrm{X}^{2} \Sigma^{+}\right)$with acetylene, $\mathrm{C}_{2} \mathrm{H}_{2}\left(\mathrm{X}^{1} \Sigma^{+}{ }_{\mathrm{g}}\right)$. J. Chem. Phys. 2000, 113, 8656-8666.

99. Balucani, N.; Asvany, O.; Chang, A.H.H.; Lin, S.H.; Lee, Y.T.; Kaiser, R.I.; Bettinger, H.F.; Schleyer, P.V.; Schaefer, H.F. Crossed beam reaction of cyano radicals with hydrocarbon molecules. I. Chemical dynamics of cyanobenzene $\left(\mathrm{C}_{6} \mathrm{H}_{5} \mathrm{CN} ; \mathrm{X}^{1} \mathrm{~A}_{1}\right)$ and perdeutero cyanobenzene $\left(\mathrm{C}_{6} \mathrm{D}_{5} \mathrm{CN} ; \mathrm{X}^{1} \mathrm{~A}_{1}\right)$ formation from reaction of $\mathrm{CN}\left(\mathrm{X}^{2} \Sigma^{+}\right)$with benzene $\mathrm{C}_{6} \mathrm{H}_{6}(\mathrm{X}$ $\left.{ }^{1} \mathrm{~A}_{1 \mathrm{~g}}\right)$ ), and $\mathrm{d}_{6}$-benzene $\mathrm{C}_{6} \mathrm{D}_{6}\left(\mathrm{X}^{1} \mathrm{~A}_{1 \mathrm{~g}}\right)$. J. Chem. Phys. 1999, 111, 7457-7471.

100. Balucani, N.; Asvany, O.; Chang, A.H.H.; Lin, S.H.; Lee, Y.T.; Kaiser, R.I.; Bettinger, H.F.; Schleyer, P.V.; Schaefer, H.F. Crossed beam reaction of cyano radicals with hydrocarbon molecules. II. Chemical dynamics of 1-cyano-1-methylallene $\left(\mathrm{CNCH}_{3} \mathrm{CCCH}_{2} ; \mathrm{X}^{1} \mathrm{~A}^{\prime}\right)$ formation from reaction of $\mathrm{CN}\left(\mathrm{X}^{2} \Sigma^{+}\right)$with dimethylacetylene $\mathrm{CH}_{3} \mathrm{CCCH}_{3}\left(\mathrm{X}^{1} \mathrm{~A}_{1}{ }^{\prime}\right)$. J. Chem. Phys. 1999, 111, 7472-7479.

101. Huang, L.C.L.; Balucani, N.; Lee, Y.T.; Kaiser, R.I.; Osamura, Y. Crossed beam reaction of the cyano radical, $\mathrm{CN}\left(\mathrm{X}^{2} \Sigma^{+}\right)$, with methylacetylene, $\mathrm{CH}_{3} \mathrm{CCH}\left(\mathrm{X}^{1} \mathrm{~A}_{1}\right)$ : Observation of cyanopropyne, $\mathrm{CH}_{3} \mathrm{CCCN}\left(\mathrm{X}^{1} \mathrm{~A}_{1}\right)$, and cyanoallene, $\mathrm{H}_{2} \mathrm{CCCHCN}\left(\mathrm{X}^{1} \mathrm{~A}^{\prime}\right)$. J. Chem. Phys. 1999, 111, 2857-2860. 
102. Kaiser, R.I.; Ochsenfeld, C.; Head-Gordon, M.; Lee, Y.T. Neutral-neutral reactions in the interstellar medium. II. Isotope effects in the formation of linear and cyclic $\mathrm{C}_{3} \mathrm{H}$ and $\mathrm{C}_{3} \mathrm{D}$ radicals in interstellar environments. Astrophys. J. 1999, 510, 784-788.

103. Kaiser, R.I.; Ochsenfeld, C.; Stranges, D.; Head-Gordon, M.; Lee, Y.T. Combined crossed molecular beams and ab initio investigation of the formation of carbon-bearing molecules in the interstellar medium via neutral-neutral reactions. Faraday Disc. 1998, 109, 183-204.

104. Kaiser, R.I.; Stranges, D.; Lee, Y.T.; Suits, A.G. Neutral-neutral reactions in the interstellar medium. I. Formation of carbon hydride radicals via reaction of carbon atoms with unsaturated hydrocarbons. Astrophys. J. 1997, 477, 982-989.

105. Kaiser, R.I.; Ochsenfeld, C.; Head Gordon, M.; Lee, Y.T.; Suits, A.G. A combined experimental and theoretical study on the formation of interstellar $\mathrm{C}_{3} \mathrm{H}$ isomers. Science 1996, 274, 1508-1511.

106. Kaiser, R.I.; Lee, Y.T.; Suits, A.G. Crossed-beam reaction of carbon atoms with hydrocarbon molecules .I. Chemical dynamics of the propargyl radical formation $\mathrm{C}_{3} \mathrm{H}_{3}\left(\mathrm{X}^{2} \mathrm{~B}_{2}\right)$, from reaction of $\left.\mathrm{C}^{3} \mathrm{P}_{\mathrm{j}}\right)$ with ethylene, $\mathrm{C}_{2} \mathrm{H}_{4}\left(\mathrm{X}^{1} \mathrm{~A}_{\mathrm{g}}\right) \mathrm{J}$. Chem. Phys. 1996, 105, 8705-8720.

107. Zhang, F.T.; Kim, Y.S.; Zhou, L.; Chang, A.H.H.; Kaiser, R.I. A crossed molecular beam study on the synthesis of the interstellar 2,4-pentadiynylidyne radical (HCCCCC). J. Chem. Phys. 2008, 129, 134313.

108. Guo, Y.; Gu, X.; Zhang, F.; Sun, B.J.; Tsai, M.F.; Chang, A.H.H.; Kaiser, R.I. Unraveling the formation of $\mathrm{HCPH}\left(\mathrm{X}^{2} \mathrm{~A}^{\prime}\right)$ molecules in extraterrestrial environments: Crossed molecular beam study of the reaction of carbon atoms, $\mathrm{C}\left({ }^{3} \mathrm{P}_{\mathrm{j}}\right)$, with phosphine, $\mathrm{PH}_{3}\left(\mathrm{X}^{1} \mathrm{~A}_{1}\right)$.J Phys. Chem. A 2007, 111, 3241-3247.

109. Gu, X.B.; Guo, Y.; Zhang, F.T.; Kaiser, R.I. Investigating the chemical dynamics of the reaction of ground-state carbon atoms with acetylene and its isotopomers. J Phys. Chem. A 2007, 111, 2980-2992.

110. Kaiser, R.I.; Stahl, F.; Schleyer, P.V.; Schaefer, H.F. Atomic and molecular hydrogen elimination in the crossed beam reaction of d1-ethinyl radicals $\mathrm{C}_{2} \mathrm{D}\left(\mathrm{X}^{2} \Sigma^{+}\right)$with acetylene, $\mathrm{C}_{2} \mathrm{H}_{2}\left(\mathrm{X}^{1} \Sigma_{\mathrm{g}}^{+}\right.$): dynamics of d1-diacetylene (HCCCCD) and d1-butadiynyl (DCCCC) formation. Phys. Chem. Chem. Phys. 2002, 4, 2950-2958.

111. Stahl, F.; Schleyer, P.V.; Bettinger, H.F.; Kaiser, R.I.; Lee, Y.T.; Schaefer, H.F. Reaction of the ethynyl radical, $\mathrm{C}_{2} \mathrm{H}$, with methylacetylene, $\mathrm{CH}_{3} \mathrm{CCH}$, under single collision conditions: Implications for astrochemistry. J. Chem. Phys. 2001, 114, 3476-3487.

112. Kaiser, R.I.; Chiong, C.C.; Asvany, O.; Lee, Y.T.; Stahl, F.; Schleyer, P.V.; Schaefer, H.F. Chemical dynamics of d1-methyldiacetylene $\left(\mathrm{CH}_{3} \mathrm{CCCCD} ; \mathrm{X}^{1} \mathrm{~A}_{1}\right)$ and d1-ethynylallene $\left(\mathrm{H}_{2} \mathrm{CCCH}\left(\mathrm{C}_{2} \mathrm{D}\right) ; \mathrm{X}^{1} \mathrm{~A}^{\prime}\right)$ formation from reaction of $\mathrm{C}_{2} \mathrm{D}\left(\mathrm{X}^{2} \Sigma^{+}\right)$with methylacetylene, $\mathrm{CH}_{3} \mathrm{CCH}(\mathrm{X}$ $\left.{ }^{1} \mathrm{~A}_{1}\right)$ J. Chem. Phys. 2001, 114, 3488-3496.

113. Casavecchia, P.; Leonori, F.; Balucani, N.; Petrucci, R.; Capozza, G.; Segoloni, E. Probing the dynamics of polyatomic multichannel elementary reactions by crossed molecular beam experiments with soft electron-ionization mass spectrometric detection. Phys. Chem. Chem. Phys. 2009, 11, 46-65.

114. Balucani, N.; Capozza, G.; Leonori, F.; Segoloni, E.; Casavecchia, P. Crossed molecular beam reactive scattering: from simple triatomic to multichannel polyatomic reactions. Int. Rev. Phys. Chem. 2006, 25, 109-163. 
115. Balucani, N.; Alagia, M.; Cartechini, L.; Casavecchia, P.; Volpi, G.G.; Sato, K.; Takayanagi, T.; Kurosaki, Y. Cyanomethylene formation from the reaction of excited nitrogen atoms with acetylene: a crossed beam and ab initio study. J. Am. Chem. Soc. 2000, 122, 4443-4450.

116. Balucani, N.; Cartechini, L.; Alagia, M.; Casavecchia, P.; Volpi, G.G. Observation of nitrogenbearing organic molecules from reactions of nitrogen atoms with hydrocarbons: a crossed beam study of $\mathrm{N}\left({ }^{2} \mathrm{D}\right)+$ ethylene. J. Phys. Chem. A 2000, 104, 5655-5659.

117. Casavecchia, P.; Balucani, N.; Cartechini, L.; Capozza, G.; Bergeat, A.; Volpi, G.G. Crossed beam studies of elementary reactions of $\mathrm{N}$ and $\mathrm{C}$ atoms and $\mathrm{CN}$ radicals of importance in combustion. Faraday Discuss. 2001, 119, 27-49.

118. Balucani, N.; Casavecchia, P. Gas-phase reactions in extraterrestrial environments: laboratory investigations by crossed molecular beams. Orig. Life Evol. Biosph. 2006, 36, 443-450.

119. Balucani, N.; Bergeat, A.; Cartechini, L.; Volpi, G.G.; Casavecchia, P.; Skouteris, D.; Rosi, M. Combined crossed molecular beam and theoretical studies of the $\mathrm{N}\left({ }^{2} \mathrm{D}\right)+\mathrm{CH}_{4}$ reaction and implications for atmospheric models of Titan. J. Phys. Chem. A, submitted.

120. Balucani, N.; Casavecchia, P.; Banares, L.; Aoiz, F.J.; Gonzalez-Lezana, T.; Honvault, P.; Launay, J.M. Experimental and theoretical differential cross sections for the $\mathrm{N}\left({ }^{2} \mathrm{D}\right)+\mathrm{H}_{2}$ reaction, J. Phys. Chem. A 2006, 110, 817-829.

121. Cartechini, L.; Bergeat, A.; Capozza, G.; Casavecchia, P.; Volpi, G.G.; Geppert, W.D.; Naulin, C.; Costes, M. Dynamics of the $\mathrm{C}+\mathrm{C}_{2} \mathrm{H}_{2}$ reaction from differential and integral cross-section measurements in crossed-beam experiments. J. Chem. Phys. 2002, 116, 5603-5611.

122. Geppert, W.D.; Naulin, C.; Costes, M.; Capozza, G.; Cartechini, L.; Casavecchia, P.; Volpi, G. G. Combined crossed-beam studies of $\left.\mathrm{C}^{3} \mathrm{P}_{\mathrm{J}}\right)+\mathrm{C}_{2} \mathrm{H}_{4} \rightarrow \mathrm{C}_{3} \mathrm{H}_{3}+\mathrm{H}$ reaction dynamics between 0.49 and $30.8 \mathrm{~kJ} \mathrm{~mol}^{-1}$. J. Chem. Phys. 2003, 119, 10607-10617.

123. Costes, M.; Daugey, N.; Naulin, C.; Bergeat, A.; Leonori, F.; Segoloni, E.; Petrucci, R.; Balucani, N.; Casavecchia, P. Crossed-beam studies on the dynamics of the $\mathrm{C}+\mathrm{C}_{2} \mathrm{H}_{2}$ interstellar reaction leading to linear and cyclic $\mathrm{C}_{3} \mathrm{H}+\mathrm{H}$ and $\mathrm{C}_{3}+\mathrm{H}_{2}$. Faraday Discuss. 2006, 133, $157-176$.

124. Leonori, F.; Petrucci, R.; Segoloni, E.; Bergeat, A.; Hickson, K.M.; Balucani, N.; Casavecchia, P. Unraveling the dynamics of the $\mathrm{C}\left({ }^{3} \mathrm{P},{ }^{1} \mathrm{D}\right)+\mathrm{C}_{2} \mathrm{H}_{2}$ reactions by the crossed molecular beam scattering technique. J. Phys. Chem. A 2008, 112, 1363-1379.

125. Leonori, F.; Petrucci, R.; Hickson, K.M.; Segoloni, E.; Balucani, N.; Le Picard, S.D.; Foggi, P.; Casavecchia, P. Crossed molecular beam study of gas phase reactions relevant to the chemistry of planetary atmospheres: the case of $\mathrm{C}_{2}+\mathrm{C}_{2} \mathrm{H}_{2}$. Planet. Space Sci. 2008, 56, 1658-1673.

126. Balucani, N.; Leonori, F.; Petrucci, R.; Hickson, K.M.; Casavecchia, P. Crossed molecular beam studies of $\mathrm{C}\left({ }^{3} \mathrm{P},{ }^{1} \mathrm{D}\right)$ and $\mathrm{C}_{2}\left(\mathrm{X}^{1} \Sigma^{+}{ }_{\mathrm{g}}, \mathrm{a}^{3} \Pi_{\mathrm{u}}\right)$ reactions with acetylene. Phys. Scr. 2008, 78, 058117.

127. Capozza, G.; Segoloni, E.; Leonori, F.; Volpi, G.G.; Casavecchia, P. Soft electron impact ionization in crossed molecular beam reactive scattering: The dynamics of the $\mathrm{O}\left({ }^{3} \mathrm{P}\right)+\mathrm{C}_{2} \mathrm{H}_{2}$ reaction. J. Chem. Phys. 2004, 120, 4557-4560.

128. Casavecchia, P.; Capozza, G.; Segoloni, E.; Leonori, F.; Balucani, N.; Volpi, G.G. dynamics of the $\mathrm{O}\left({ }^{3} \mathrm{P}\right)+\mathrm{C}_{2} \mathrm{H}_{4}$ reaction: identification of five primary product channels (vinoxy, acetyl, methyl, methylene, and ketene) and branching ratios by the crossed molecular beam technique with soft electron ionization. J. Phys. Chem. A 2005, 109, 3527-3530. 
129. Balucani, N.; Stranges, D.; Casavecchia, P.; Volpi, G.G. Crossed beam studies of the reactions of atomic oxygen in the ground ${ }^{3} \mathrm{P}$ and first electronically excited ${ }^{1} \mathrm{D}$ states with hydrogen sulfide. $J$. Chem. Phys. 2004, 120, 9571-9582.

130. Alagia, M.; Balucani, N.; Casavecchia, P.; Stranges, D.; Volpi, G.G. Crossed beam studies of four-atom reactions: the dynamics of $\mathrm{OH}+\mathrm{D}_{2}$. J. Chem. Phys. 1993, 98, 2459.

131. Alagia, M.; Balucani, N.; Casavecchia, P.; Stranges, D.; Volpi, G.G. Crossed beam studies of four-atom reactions: the dynamics of $\mathrm{OH}+\mathrm{CO}$. J. Chem. Phys. 1993, 98, 8341.

132. Leonori, F.; Petrucci, R.; Balucani, N.; Hickson, K.M.; Hamberg, M.; Geppert, W.D.; Casavecchia, P.; Rosi, M. Combined crossed beam and theoretical studies of the $\mathrm{S}\left({ }^{1} \mathrm{D}\right)+\mathrm{C}_{2} \mathrm{H}_{2}$ reaction. J. Phys. Chem. A 2009, 113, 4330-4339.

133. Leonori, F.; Petrucci, R.; Balucani, N.; Casavecchia, P.; Rosi, M.; Berteloite, C.; Le Picard, S.D.; Canosa, A.; Sims, I.R. Observation of organosulfur products (thiovinoxy, thioketene and thioformyl) in crossed-beam experiments and low temperature rate coefficients for the reaction $\mathrm{S}\left({ }^{1} \mathrm{D}\right)+\mathrm{C}_{2} \mathrm{H}_{4}$. Phys. Chem. Chem. Phys. 2009, in press.

134. Huang, C.; Li, W.; Estillore, A.D.; Suits, A.G. Dynamics of CN plus alkane reactions by crossedbeam dc slice imaging. J. Chem. Phys. 2008, 129, 074301.

135. Zhang, F.; Kim, S.; Kaiser, R.I. A crossed molecular beams study of the reaction of the ethynyl radical $\left(\mathrm{C}_{2} \mathrm{H}\left(\mathrm{X}^{2} \Sigma^{+}\right)\right)$with allene $\left(\mathrm{H}_{2} \mathrm{CCCH}_{2}\left(\mathrm{X}^{1} \mathrm{~A}_{1}\right)\right)$. Phys. Chem. Chem. Phys. 2009, in press. DOI: $10.1039 / \mathrm{b} 822366 \mathrm{a}$.

136. Kaiser, R.I.; Ting, J.; Huang, L.C.L.; Balucani, N.; Asvany, O.; Lee, Y.T.; Chan, O.; Stranges, D.; Gee, D. A versatile source to produce high intensity, pulsed supersonic radical beams for crossed beam experiments - the cyano radical $\mathrm{CN}\left(\mathrm{X}^{2} \Sigma^{+}\right)$, as a case study. Rev. Sci. Instrum. 1999, 70, 4185-4184.

137. Guo, Y.; Mebel, A.M.; Zhang, F.; Gu, X.; Kaiser, R.I. Crossed molecular beam studies of the reactions of allyl radicals, $\mathrm{C}_{3} \mathrm{H}_{5}\left(\mathrm{X}^{2} \mathrm{~A}_{2}\right)$, with methylacetylene $\left(\mathrm{CH}_{3} \mathrm{CCH}\left(\mathrm{X}^{1} \mathrm{~A}_{1}\right)\right)$, allene $\left(\mathrm{H}_{2} \mathrm{CCCH}_{2}\left(\mathrm{X}^{1} \mathrm{~A}_{1}\right)\right)$, and their isotopomers. J. Phys. Chem. A 2007, 111, 4914-4921.

138. Gu, X.; Kaiser, R.I. Reaction dynamics of phenyl radicals in extreme environments: a crossed molecular beam study. Acc. Chem. Res. 2009, 42, 290-302.

139. Leonori, F.; Balucani, N.; Capozza, G.; Segoloni, E.; Stranges, D.; Casavecchia, P. Crossed beam studies of radical-radical reactions: $\left.\mathrm{O}^{3} \mathrm{P}\right)+\mathrm{C}_{3} \mathrm{H}_{5}$ (allyl). Phys. Chem. Chem. Phys. 2007, 9, 1307-1311.

140. Alagia, M.; Aquilanti, V.; Ascenzi, D.; Balucani, N.; Cappelletti, D.; Cartechini, L.; Casavecchia, P.; Pirani, F.; Sanchini, G.; Volpi, G.G. Magnetic analysis of supersonic beams of atomic oxygen, nitrogen, and chlorine generated from a radio-frequency discharge. Israel J. Chem. 1997, 37, 329-342.

141. Bettens, R.P.A.; Lee, H.H.; Herbst, E. The importance of classes of neutral-neutral reactions in the production of complex interstellar-molecules. Astrophys. J. 1995, 443, 664-674.

142. Turner, B.E. Detection of Interstellar Cyanoacetylene. Astrophys. J. 1971, 163, L35-L41.

143. Cernicharo, J.; Guelin, M.; Kahane, X. A lambda $2 \mathrm{~mm}$ molecular line survey of the C-star envelope IRC + 10216. Astronom. Astrophys. Suppl. Ser. 2000, 142, 181-215.

144. Wyrowski, F.; Schilke, P.; Walmsley, C.M. Vibrationally excited $\mathrm{HC}_{3} \mathrm{~N}$ toward hot cores. Astronom. Astrophys. 1999, 341, 882-895. 
145. Bell, M.B.; Feldman, P.A.; Travers, M.J.; McCarthy, M.C.; Gottlieb C.A.; Thaddeus, P. Detection of $\mathrm{HC}_{11} \mathrm{~N}$ in the Cold Dust Cloud TMC-1 Astrophys. J. 1997, 483, L61-L64.

146. Bell, M.B.; Watson, J.K.G.; Feldman, P.A.; Travers, M.J. The excitation temperatures of $\mathrm{HC}_{9} \mathrm{~N}$ and other long cyanopolyynes in TMC-1. Astrophys. J. 1998, 508, 286-290.

147. Broten, N.W; MacLeod, J.M.; Avery, L.W.; Friberg, P.; Hjalmarson, A.; Hoglund, B.; Irvine, W.M.The detection of interstellar methylcyanoacetylene. Astrophys. J. 1984, 276, L25-L29.

148. Nummelin, A.; Bergman, P. Vibrationally excited vinyl cyanide in Sgr B2(N). Astron. Astrophys. 1999, 341, L59-L62.

149. Guelin, M.; Neininger, N.; Cernicharo, J. Astronomical detection of the cyanobutadiynyl radical $\mathrm{C}_{5}$ N. Astron. Astrophys. 1998, 335, L1-L4.

150. Guelin, M.; Mezaoui, A.; Friberg, P. Astronomical study of the $\mathrm{C}_{3} \mathrm{~N}$ and $\mathrm{C}_{4} \mathrm{H}$ radicals Hyperfine interactions and Rho-type doubling. Astron. Astrophys. 1982, 109, 23-31.

151. Takagi, N.; Fukuzawa, K.; Osamura, Y.; Schaefer III, H.F. Ion-molecule reactions producing $\mathrm{HC}_{3} \mathrm{NH}^{+}$in interstellar space: forbiddenness the reaction between cyclic $\mathrm{C}_{3} \mathrm{H}_{3}{ }^{+}$and the $\mathrm{N}$ atom. Astrophys. J. 1999, 525, 791-798.

152. Smith, I.W.M.; Sims, I.R. General Discussion. J. Chem. Soc. Faraday Trans. 1993, 89, 2165.

153. Fukuzawa, K.; Osamura, Y. Molecular orbital study of neutral-neutral reactions concerning $\mathrm{HC}_{3} \mathrm{~N}$ formation in interstellar space. Astrophys. J. 1997, 489, 113-121; and references therein.

154. Winstanley, N.; Nejad, L.A.M. Cyanopolyyne Chemistry in TMC-1. Astrophys. Space Sci. 1996, 240, 13-37.

155. Kunde, V.G., Aikin, A.C., Hand, R.A., Jennings, D.E., Maguire, W.C., Samuelson, R.E. $\mathrm{C}_{4} \mathrm{H}_{2}$, $\mathrm{HC}_{3} \mathrm{~N}$, and $\mathrm{C}_{2} \mathrm{~N}_{2}$ in Titan's atmosphere. Nature 1981, 292, 686-688.

156. Teanby, N.A.; Irwin, P.G.J.; de Koka, R.; Vinatier, S.; Bézard, B.; Nixon, C.A.; Flasar, F.M.; Calcutt, S.B.; Bowles, N.E.; Fletcher, L.; Howett, C.; Taylor, F.W. Vertical profiles of HCN, $\mathrm{HC}_{3} \mathrm{~N}$, and $\mathrm{C}_{2} \mathrm{H}_{2}$ in Titan's atmosphere derived from Cassini/CIRS data. Icarus 2007, 186, 364-384.

157. Bezard, B.; Marten, A.; Paubert, G. Detection of acetonitrile on Titan. Bull. Am. Astron. Soc. 1993, 25, 1100-1104.

158. Carty, D.; Le Page, V.; Sims, I.R.; Smith, I.W.M. Low temperature rate coefficients for the reactions of $\mathrm{CN}$ and $\mathrm{C}_{2} \mathrm{H}$ radicals with allene $\left(\mathrm{CH}_{2}=\mathrm{C}=\mathrm{CH}_{2}\right)$ and methyl acetylene $\left(\mathrm{CH}_{3} \mathrm{C}\right.$ equivalent to $\mathrm{CH})$. Chem. Phys. Lett. 2001, 344, 310-316.

159. Georgievskii, Y.; Klippenstein, S.J. Strange kinetics of the $\mathrm{C}_{2} \mathrm{H}_{6}+\mathrm{CN}$ reaction explained. $J$. Phys. Chem. A 2007, 111, 3802-3811.

160. Choi, N.; Blitz, M.A.; McKee, K.; Pilling, M.J.; Seakins, P.W. H atom branching ratios from the reactions of $\mathrm{CN}$ radicals with $\mathrm{C}_{2} \mathrm{H}_{2}$ and $\mathrm{C}_{2} \mathrm{H}_{4}$. Chem. Phys. Lett. 2004, 384, 68-72.

161. Gannon, K.L.; Glowacki, D.R.; Blitz, M.A.; Hughes, K.J.; Pilling, M.J.; Seakins, P.W. H atom yields from the reactions of $\mathrm{CN}$ radicals with $\mathrm{C}_{2} \mathrm{H}_{2}, \mathrm{C}_{2} \mathrm{H}_{4}, \mathrm{C}_{3} \mathrm{H}_{6}$, trans-2- $\mathrm{C}_{4} \mathrm{H}_{8}$, and iso- $\mathrm{C}_{4} \mathrm{H}_{8}$. J. Phys. Chem. A 2007, 111, 6679-6692.

162. Trevitt, A.J.; Goulay, F.; Meloni, G.; Osborn, D.L.; Taatjes, C.A.; Leone, S.R. Isomer-specific product detection of $\mathrm{CN}$ radical reactions with ethene and propene by tunable VUV photoionization mass spectrometry. Int. J. Mass Spectr. 2009, 280, 113-118. 
163. Herbert, L.; Smith, I.W.M.; Rowland, D.; Spencer-Smith, R.D. Rate constants for the elementary reactions between $\mathrm{CN}$ radicals and $\mathrm{CH}_{4}, \mathrm{C}_{2} \mathrm{H}_{6}, \mathrm{C}_{2} \mathrm{H}_{4}, \mathrm{C}_{3} \mathrm{H}_{6}$, and $\mathrm{C}_{2} \mathrm{H}_{2}$ in the range $-295<\mathrm{T} / \mathrm{K}<$ 700K. Int. J. Chem. Kinet. 1992, 24, 791-802.

164. Chin, Y.; Kaiser, R.I.; Lemme, C.; Henkel, C. Detection of interstellar cyanoallene and its implications for astrochemistry. AIP Conf. Proc. 2006, 855, 149-153.

165. Lovas, F.J.; Remijan, A.J.; Hollis, J.M.; Jewell, P.R.; Snyder, L.E. Hyperfine structure identification of interstellar cyanoallene toward TMC-1. Astrophys. J. 2006, 637, L37-L40.

166. van Dishoeck, E.F.; Black, J.H. The excitation of interstellar $\mathrm{C}_{2}$. Astrophys. J. 1982, 258, 533-547.

167. Altwegg, K.; Balsinger, H.; Geiss, J. Composition of the volatile material in Halley's coma from in situ measurements. Space Sci. Rev. 1999, 90, 3-18.

168. Geiss, J.; Altwegg, K.; Balsinger, H.; Graf, S. Rare atoms, molecules and radicals in the coma of P/Halley. Space Sci. Rev. 1999, 90, 253-268.

169. Sorkhabi, O.; Blunt, V.M.; Lin, H.; A’Hearn, M.F.; Weaver, H.A.; Arpigny, C.; Jackson, W.M. Using photochemistry to explain the formation and observation of $\mathrm{C}_{2}$ in comets. Planet. Space Sci. 1997, 45, 721-730.

170. Mebel, A. M.; Hayashi, M.; Jackson, W. M.; Wrobel, J.; Green, M.; Xu, D.; Lin, S. H. Branching ratios of $\mathrm{C}_{2}$ products in the photodissociation of $\mathrm{C}_{2} \mathrm{H}$ at $193 \mathrm{~nm}$. J. Chem. Phys. 2001, 114, 9821-9831.

171. Becker, K.H.; Donner, B.; Dinis, C.M.F.; Geiger, H.; Schmidt, F., Wiesen, P. Kinetics of the $\mathrm{C}_{2}\left(a^{3} \Pi_{\mathrm{u}}\right)$ radical reacting with selected molecules and atoms. Z. Phys. Chem. 2000, 214, 503-517.

172. Pasternack, L.; McDonald, J.R. Reactions of $\mathrm{C}_{2}\left(\mathrm{X}^{1} \Sigma_{\mathrm{g}}^{+}\right)$produced by multi-photon UV-excimer laser photolysis. Chem. Phys. 1979, 43, 173-182.

173. Pitts, W.M.; Pasternack, L.; McDonald, J.R. Temperature-dependence of the $\mathrm{C}_{2}\left(\mathrm{X}^{1} \Sigma_{\mathrm{g}}^{+}\right)$reaction with $\mathrm{H}_{2}$ and $\mathrm{CH}_{4}$ and $\mathrm{C}_{2}\left(\mathrm{X}^{1} \Sigma_{\mathrm{g}}^{+}\right.$and $\mathrm{a}^{3} \Pi_{\mathrm{u}}$ equilibrated states $)$ with $\mathrm{O}_{2}$. Chem. Phys. 1982, 68, 417-422.

174. Reisler, H.; Mangir, M.S.: Wittig, C. Kinetics of free-radicals generated by IR laser photolysis. 4. Intersystem crossings and reactions of $\mathrm{C}_{2}\left(\mathrm{X}^{1} \Sigma_{\mathrm{g}}^{+}\right)$and $\mathrm{C}_{2}\left(\mathrm{a}^{3} \Pi_{\mathrm{u}}\right)$ in the gaseous-phase. J. Chem. Phys. 1980, 73, 2280-2286.

175. Daugey, N.; Caubet, P.; Bergeat, A.; Costes, M.; Hickson, K. M. Reaction kinetics to low temperatures. Dicarbon + acetylene, methylacetylene, allene and propene from $77 \leq \mathrm{T} \leq 296 \mathrm{~K}$. Phys. Chem. Chem. Phys. 2008, 10, 729-737.

176. Herron, J.T. 1999. Evaluated chemical kinetics data for reactions of $\mathrm{N}\left({ }^{2} \mathrm{D}\right), \mathrm{N}\left({ }^{2} \mathrm{P}\right)$ and $\mathrm{N}_{2}\left(\mathrm{~A}^{3} \sum_{\mathrm{u}}{ }^{+}\right)$ in the gas phase. J. Phys. Chem. Ref. Data 1999, 28, 1453-1483.

177. Yung,Y. L. An update of nitrile photochemistry in Titan, Icarus 1987, 72, 468-472.

178. Kurosaki, Y.; Takayanagi, T.; Sato, K.; Tsunashima, S. Ab initio molecular orbital calculations of the potential energy surfaces for the $\mathrm{N}\left({ }^{2} \mathrm{D}\right)+\mathrm{CH}_{4}$ reaction. J. Phys. Chem. A 1998, 102, 254-259.

179. Umemoto, H.; Nakae, T.; Hashimoto, H.; Kongo, K.; Kawasaki M. Reactions of N( $\left.{ }^{2} \mathrm{D}\right)$ with methane and deuterated methanes, J. Chem. Phys. 1998, 109, 5844-5848. 
180. Balucani, N.; Casavecchia, P. Neutral-neutral gas-phase reactions in extraterrestrial environments: laboratory investigations by crossed molecular beams. AIP Conference Proceedings 2006, 855, 17-30.

181. Fujii, T.; Arai, N. Analysis of N-containing hydrocarbon species produced by a $\mathrm{CH}_{4} / \mathrm{N}_{2}$ microwave discharge: Simulation of Titan's atmosphere. Astrophys J. 1999, 519, 858-863.

182. Teslja, A.; Nizamov, B.; Dagdigian, P.J. The electronic spectrum of methyleneimine. J. Phys. Chem. A 2004, 108, 4433-4439.

183. Larson, C.; Ji, Y.Y.; Samartzis, P., Wodtke, A.M.; Lee, S.H.; Lin, J.J.M.; Chaudhuri, C.; Ching T.T. Collision-free photochemistry of methylazide: Observation of unimolecular decomposition of singlet methylnitrene. J. Chem. Phys. 2006, 125, 133302.

184. Takayanagi, T.; Kurosaki, Y.; Sato, K.; Tsunashima, S. Ab initio molecular orbital study of the $\mathrm{N}\left({ }^{2} \mathrm{D}\right)+$ ethylene reaction. J. Phys. Chem. A 1998, 102, 10391-10398.

185. Leonori, F.; Petrucci, R.; Stazi, M.; Balucani, N.; Casavecchia, P.; Skouteris, D.; Rosi, M. Combined crossed-beam and theoretical studies of the $\mathrm{N}\left({ }^{2} \mathrm{D}\right)+\mathrm{C}_{2} \mathrm{H}_{6}$ reaction. In preparation.

186. Israel, G.; Szopa, C.; Raulin, F.; Cabane, M.; Niemann, H.B.; Atreya, S.K.; Bauer, S.J.; Brun, J.F.; Chassefiere, E.; Coll, P.; Conde, E.; Coscia, D.; Hauchecorne, A.; Millian, P.; Nguyen, M.J.; Owen, T.; Riedler, W.; Samuelson, R.E.; Siguier, J.M.; Steller, M.; Sternberg, R.; Vidal-Madjar, C. Complex organic matter in Titan's atmospheric aerosols from in situ pyrolysis and analysis. Nature 2005, 438, 796-799.

187. Yamada, M.; Osamura, Y.; Kaiser, R.I. A comprehensive investigation on the formation of organo-sulfur molecules in dark clouds via neutral-neutral reactions. Astronom. Astrophys. 2002, 395, 1031-1044.

188. Petrie, S. Formation of interstellar CCS and CCCS: A case for radical/neutral chemistry? Mon. Not.R. Astronom. Soc. 1996, 281, 666-672.

189. Wakelam, V.; Ceccarelli, C.; Castets, A.; Lefloch, B.; Loinard, L.; Faure, A.; Schneider, N.; Benayoun, J.J. Sulphur chemistry and molecular shocks: The case of NGC 1333-IRAS 2. Astron. Asrophys. 2005, 437, 149-158.

190. Wakelam, V.; Caselli, R.; Ceccarelli, C.; Herbst, E.; Castets, A. Resetting chemical clocks of hot cores based on S-bearing molecules. Astron. Asrophys. 2004, 422, 159-169.

191. Wakelam, V.; Castets, A.; Ceccarelli, C.; Lefloch, B.; Caux, E.; Pagani, L. Sulphur-bearing species in the star forming region L1689N. Astron. Asrophys. 2004, 413, 609-622.

192. Dello Russo, N.; DiSanti, M.A.; Mumma, M.J.; Magee-Sauer, K.; Rettig, T.W. Carbonyl sulfide in comets C/1996 B2 (Hyakutake) and C/1995 O1 (Hale-Bopp): Evidence for an extended source in Hale-Bopp. Icarus, 1998, 135, 377-388.

193. Noll, K.S.; McGrath, M. A.; Trafton, L. M.; Atreya, S. K.; Caldwell, J.J.; Weaver, H. A.; Yelle, R. V.; Barnet, C.; Edgington, S. HST spectroscopic observations of Jupiter after the collision of comet Shoemaker-Levy 9. Science 1995, 267, 1307-1313.

194. Atreya, S.K.; Edginton, S.G.; Trafton, L. M.; Caldwell, J.J.; Noll, K. S.; Weaver, H. A. Abundances of ammonia and carbon-disulfide in the jovian stratosphere following the impact of comet Shoemaker-Levy 9. Geophys. Res. Lett. 1995, 22, 1625-1628. 
195. Kaiser, R. I.; Ochsenfeld, C.; Head-Gordon, M.; Lee, Y. T. The formation of HCS and HCSH molecules and their role in the collision of comet Shoemaker-Levy 9 with Jupiter. Science 1998, 279, 1181.

196. Kaiser, R. I.; Yamada, M.; Osamura, Y. A crossed beam and ab initio investigation of the reaction of hydrogen sulfide, $\mathrm{H}_{2} \mathrm{~S}\left(\mathrm{X}^{1} \mathrm{~A}_{1}\right)$, with dicarbon molecules, $\mathrm{C}_{2}\left(\mathrm{X}^{1} \Sigma_{\mathrm{g}}^{+}\right)$. J. Phys. Chem. A 2002, 106, 4825.

197. Woon, D.E. Quantum chemical evaluation of the astrochemical significance of reactions between S atom and acetylene or ethylene. J. Phys. Chem. A 2007, 111, 11249-11253.

198. Kim, M. H.; Li, W.; Lee, S.K.; Suits, A.G. Probing of the hot-band excitations in the photodissociation of OCS at $288 \mathrm{~nm}$ by DC slice imaging. Can. J. Chem. 2004, 82, 880-884.

199. Black, G.; Jusinski, L.E. Branching ratio for $\mathrm{S}\left(3^{3} \mathrm{P}_{\mathrm{J}}\right)$ AND $\mathrm{S}\left(3^{1} \mathrm{D}_{2}\right)$ atom production in the photodissociation of $\mathrm{CS}_{2}$ at $193 \mathrm{~nm}$. Chem. Phys. Lett., 1986, 124, 90-92.

200. Cook, P.A.; Langford, S.R.; Dixon, R.N.; Ashfold M.N.R. An experimental and ab initio reinvestigation of the Lyman- $\alpha$ photodissociation of $\mathrm{H}_{2} \mathrm{~S}$ and $\mathrm{D}_{2} \mathrm{~S}$. J. Chem. Phys. 2001, 114, 1672-1684.

201. Janssen, L.M.C.; van der Loo, M.P.J.; Groenenboom, G.C.; Wu, S.-M.; Radenović, D.C.; van Roij, A.J.A.; Garcia, I.A.; Parker, D.H. Photodissociation of vibrationally excited SH and SD radicals at 288 and $291 \mathrm{~nm}$ : The $\mathrm{S}\left({ }^{1} \mathrm{D}_{2}\right)$ channel. J. Chem. Phys. 2007, 126, 094304.

202. Vasyunin, A.I.; Semenov, D.; Wakelam, V.; Herbst, E.; Sobolev, A.M. Chemistry in protoplanetary disks: A sensitivity analysis. Astrophys. J. 2008, 672, 629-641.

203. Wakelam, V.; Loison, J.C.; Herbst, E.; Talbi, D.; Quan, D.; Caralp, F. A sensitivity study if the neutral-neutral reactions $\mathrm{C}+\mathrm{C}_{3}$ and $\mathrm{C}+\mathrm{C}_{5}$ in cold dense interstellar clouds. Astron. Asrophys. 2009, 495, 513-521.

204. Carrasco, N.; Alcaraz, C.; Dutuit, O.; Plessis, S.; Thissen, R.; Vuitton, V.; Yelle, R.; Pernot, P. Sensitivity of a Titan ionospheric model to the ion-molecule reaction parameters. Planet. Space Sci. 2008, 56, 1644-1657.

205. Dobrijevic, M.; Carrasco, N.; Hebrard, E.; Pernot, P. Epistemic bimodality and kinetic hypersensitivity in photochemical models of Titan's atmosphere Planet. Space Sci. 2008, 56, 1630-1643.

(C) 2009 by the authors; licensee Molecular Diversity Preservation International, Basel, Switzerland. This article is an open-access article distributed under the terms and conditions of the Creative Commons Attribution license (http://creativecommons.org/licenses/by/3.0/). 